\title{
La biblioteca del Sacro Convento de Calatrava
}

\author{
Blas Casado Quintanilla *
}

En el estado actual de las investigaciones en el campo de las bibliotecas no se hace necesario presentar una o varias páginas de argumentos a favor de la conveniencia o no de su estudio. Hoy es comúnmente admitido que el conocimiento de las bibliotecas es un medio de penetración en la historia de la cultura y de las mentalidades de nuestros antepasados, individual o colectivarnente. Son abundantes los trabajos dedicados a analizar un conjunto de libros, de mayor o menor cuantía, bien pertenecieran a personas particulares, civiles o eclesiásticas, o a comunidades monásticas o catedralicias. Autores como Tomás Marín, Charles B. Faulhaber, Maxime Chevalier, Julián Martín Abad o los diversos artículos de Livre et lecture en España et France sous l'ancienne regimen, son un extraordinario exponente de la abundancia de estudios realizados sobre otras tantas bibliotecas ${ }^{1}$. Pero ignoramos que se halla realizado un estudio de la biblioteca de una comunidad peculiar como es la formada por los miembros de una orden militar peninsular.

* UNED.

"Tomás Marin, "Bibliotecas eclesiásticas", Diccionario de Historia Eclesiástica de España, tomo I, Madrid 1972, págs. 250-262. Charles B. FAULHABER, Libros y bibliotecas en la España Medieval, Valencia 1987, recoge todos los trabajos de los que tiene noticias sobre bibliotecas medievales, incluso por regiones, acompañando una valoración de cada trabajo. Maxime CHEVALIER, Lectura y lectores en la España de los siglos XVI y XVII, Madrid 1976. Julián Martín ABAD, Manuscritos de España. Guía de catálogos impresos, Madrid 1989. obra en la que el subtítulo aclara el valioso y útil contenido de la publicación. Livre et lecture en España et en France sous l'ancienne regime. Colloque de la Casa de Velázquez, Paris 1981, de donde queremos destacar entre otros estos dos artículos: Miguel Angel Ladero Quesada y M. C. Quintanilla Raso, "Las bibliotecas de la alta nobleza castellana en el siglo XV" (págs. 47-62) y Josep TRENCHS ODENA, "La cultura jurídico-piadosa del cabildo conquense (1450-1476)", págs. 35-46. 
Los autores citados recogen de forma casi exhaustiva todos los trabajos realizados sobre bibliotecas, con un claro predominio de los estudios de bibliotecas particulares, dándonos a conocer la importancia de la cultura de algunas personas y por ende su capacidad de influencia en su entorno social.

En nuestro caso la óptica personalista predominante en los estudios realizados sobre bibliotecas es insuficiente. Nos encontramos ante el inventario de la biblioteca de un grupo de personas que formaba la clase dirigente de un amplio territorio con base en el Campo de Calatrava ${ }^{2}$ y sobre el que ejercía una fuerte presión económica, administrativa, cultural y religiosa ${ }^{3}$. A través del estudio de su biblioteca podemos atisbar el nivel de formación de los miembros que conformaban la Orden de Calatrava hasta el primer cuarto del siglo xvi. Podría afirmarse que esta biblioteca era utilizada solamente por los clérigos conventuales y que debería catalogarse simplemente dentro del capítulo de las bibliotecas eclesiásticas. A nuestro entender esto equivaldría a desviar y simplificar la cuestión. Admitamos que los clérigos eran los que hacían uso preferente de los libros, pero tendremos que reconocer también que el comendador de Daimiel, como veremos, tenía en su casa-encomienda, un elevado número de títulos; habrá que reconocer que los libros de "re militare" serían del gusto de los caballeros de la Orden, así como otros muchos libros de crónicas y aquéllos de derecho que sirvieran de base para aprender a realizar una buena administración de los bienes de la Orden que los caballeros pudieran tener bajo su responsabilidad en las encomiendas. Los libros a nuestro entender eran útiles para todos los de la Orden, y así, como veremos, en sus reuniones capitulares mostraban una y otra vez su preocupación por el tema de los libros y la adecuada conservación de los mismos en la biblioteca.

${ }^{2}$ En las últimas décadas del siglo $x v$ el señorío de la Orden de Calatrava se extendía por casi la totalidad de la actual provincia de Ciudad Real, el extremo suroccidental de la de Guadalajara y un amplio número de poblaciones de Jaén y otros núcleos en Toledo, Murcia, Córdoba, Huelva, Cáceres, Sevilla y Madrid.

Para su gobierno y explotación este señorío estaba dividido en tres grandes partidos: Andalucía, Zorita y Campo de Calatrava. Existían además una subdivisión en cuanto a responsabilidades administrativas, en un total de 46 encomiendas (28 en el Campo de Calatrava, 11 en Andalucía y 7 en Zorita) y 6 prioratos.

${ }^{3}$ Los libros de visitas nos dan una muestra permanente del control de los comendadores y prioratos y las poblaciones situadas bajo su responsabilidad. En cuanto a obras de consulta obligada para una mejor comprensión de la importancia de la Orden en su señorío y en los aspectos y época que a nosotros atañe, ver: Emma SOLANo, La Orden de Calatrava en el siglo xv, Sevilla 1978 y Francisco Fernandez Izouierdo, La Orden de Calatrava en el siglo XVI, Tesis Doctoral Inédita, Universidad Complutense, Madrid 1986. 
Detenernos en el estudio de la biblioteca de una orden militar supone destacar un aspecto de esta institución que ha sido escasamente estudiado y ha quedado frecuentemente oscurecido por la vertiente militar. Ciertarnente Calatrava tuvo un carácter militar tanto al principio con el abad Raimundo y el monje Diego Velázquez, como todo a lo largo del periodo de la reconquista. Con el paso del tiempo en su seno se formó una verdadera comunidad conventual ${ }^{4}$. Durante las últimas décadas del siglo XIV se acaba la reconquista, a excepción del reino de Granada. La institución Calatrava comienza a organizarse para el tiempo de paz.

A fin de situar la biblioteca en su auténtico entorno creemos conveniente dedicar unos epígrafes a los "maestros" docentes en Calatrava y otro a los primeros calatravos que accedieron a las universidades de Alcalá de Henares y de Salamanca a costa de la Orden. La existencia de unos y otros puede ser considerada como causa impulsora de la formación de la biblioteca.

\section{LOS MAESTROS}

Coincidiendo con el principio del siglo $\mathrm{XV}$, constatamos que las definiciones de la Orden de 1437, las de 1448 y las de 1462 reclaman la presencia de un "maestro" para enseñar a los novicios, cuyo salario ha de recaer sobre el maestre ${ }^{5}$. Debía de enseñar diversas disciplinas, no especificadas en el texto, especialmente gramática. Este mismo requeri-

"Blas CASAdo Quintanilla, “Intitulatio y Directio en la documentación de Calatrava». Cuadernos de Estudios Manchegos, en prensa, en el número próximo a aparecer.

${ }^{5}$ Biblioteca de Santa Cruz de Valladolid, Ms. 335, fol. 14: "Nescesario es que en el convento sea residente continuo un maestro para ynstruir y enseñar a los mancebos religiosos en la arte de gramatica y en otras sciencias hasta tanto que sea algún religioso enseñado e suficiente para enseñar a los otros". En esta última línea queda de manifiesto el propósito de los calatravos de disponer de maestros de entre los mismos miembros de la Orden, según estudiaremos más adelante. 
miento se hace en las definiciones dadas por fray Guillermo, abad de Morimundo, el año $1468^{6}$.

A partir de 1497 o quizá antes, por donación de un juro de 25.000 maravedíes que dejó el sacristán mayor fray Bartolomé ${ }^{7}$, se pagaría a un lector en Teología y Artes a fin de que instruyese a los conventuales en esas y otras disciplinas. Este nuevo "maestro" sería nombrado por el prior del Sacro Convento de Calatrava.

Aunque algún documento de Calatrava, anterior a las definiciones citadas, recoge la existencia de un maestro con fines educativos ${ }^{8}$, es ahora, desde mediados del siglo $x \mathrm{~V}$, cuando se institucionaliza la presencia de los maestros o educadores con todas las formalidades y con un salario específico. Queremos relacionar esta nueva situación con la nueva forma de vida de los calatravos. Es la era de la paz. Es necesario desarrollar una organización interna más acorde con el tiempo de paz.

Se menciona también a un «Predicador del Campo de Calatrava" que asimismo parece tener relación con la enseñanza de los frailes ${ }^{9}$. Este predicador es una figura especialmente importante tanto desde el punto de vista de la biblioteca, por la exigencia de determinados libros que su oficio requiere, como desde la óptica de la exención religiosa de la que disfrutaba la Orden de Calatrava. La biblioteca recoge más de sesenta libros con el título de "sermones" y otros muchos que aún no llevando este titular podrían servir para la misma finalidad. También hemos encontrado algún libro sobre el modo de predicar. Ninguna biblioteca acumula tantos libros de un mismo tema, sino es porque son necesarios para desarrollar la actividad a la que hacen referencia los títulos: la predicación, extraordinario medio de influencia sobre todo el territorio señorial. Una biblioteca no nace por generación espontánea. Los calatravos no compraron tantos títulos de un mismo tema de una sola vez, sino que fueron adquiriéndolos lentamente, a medida que iba creciendo la necesidad de contar con ellos.

\footnotetext{
${ }^{6}$ AHN. OO. MM. Calatrava. Libros mss. 1270c, fol. 21v. Se repite prácticamente el mismo texto.

7 Francisco Fernandez IzQuierdo, obra citada, pág. 279. En el inventario de la biblioteca de Calatrava aparece el asiento de un libro de Cosas del sacristán fray Bartolomé, sin que exista ninguna aclaración sobre el contenido de este volumen.

${ }^{8}$ Blas Casado Quintanilla, "Un privilegio rodado expedido por el maestre de Calatrava", Anuario de Estudios medievales, 13, 1983, 143.

${ }^{9}$ Francisco Fernandez IzQuierdo, obra citada, pág. 280.
} 
La exención eclesiástica mencionada comporta unos privilegios que no es el momento de analizar, al mismo tiempo que crea unas obligaciones. Por el lado del privilegio los calatravos tenían a su cargo el nombramiento de los sacerdotes para la atención espiritual de todo su señorio. Por el lado de las obligaciones para cumplir con esta misión evangelizadora se hace ineludible formar a un elevado número de sacerdotes cuya misión primordial estaría relacionada con la predicación, aspecto éste que estaría bajo la responsabilidad del "Predicador del Campo de Calatrava". Sin duda alguna aquel privilegio y esta obligación tendrian un efecto positivo sobre la formación de los calatravos en general y de la biblioteca en particular. No en vano, entonces, el capítulo general de la Orden reclama una y otra vez la presencia de maestros en el Convento de Calatrava. En este mismo capítulo, los capitulares, lamentarán la desaparición de muchos libros de la biblioteca y reclamarán el establecimiento de unas normas estrictas para su control; piden, también, que se aten con cadenas y que se haga un inventario exhaustivo de los volúmenes, que se reclame a las personas los libros que tienen del convento, aunque sea en concepto de préstamo controlado, como veremos más abajo. Esta actitud denota la alta estima que tenian los calatravos por los libros, como parte de su patrimonio y como medio para mejorar su preparación intelectual.

Hay dos asientos del inventario, uno redactado de forma genérica y otro, el número 327 , con redacción concreta, que podemos incluir bajo este epígrafe de los maestros del Sacro Convento de Calatrava. El primero dice: "Hallaronse más veinte e un libros de latín y de mano, maltratados e que no se pueden bien aprovechar de ellos" ( $\mathrm{Al}$ margen izquierdo: ;ojo!). El segundo se refiere a "Un libro de doctrina pueril» (AI margen izquierdo: “Cartillas»).

En otras ocasiones el escribano indica que algunos libros de diversas disciplinas están "quemados» o "maltratados", a nuestro entender como consecuencia del descuido o del simple uso. Aquí, por el contrario, se habla de una veintena de libros y todos referidos a una sola materia: el latín. Lamentamos el carácter lacónico del listado porque sólo nos permite aventurar hipótesis de trabajo, pero entendemos que el número de veintiuno podría referirse a los escolares que hacen uso frecuente de unos «libros de texto" para el aprendizaje del latín; máxime si en el asiento 327 se anota un solo libro y al margen se escribe "cartillas", en plural, en clara referencia, por el título del volumen y por el calificativo empleado, a las actividades escolares dentro del propio convento. 


\section{LOS UNIVERSITARIOS DE CALATRAVA}

En nuestro intento de buscar los origenes de esta biblioteca, hemos de añadir a la causa ya mencionada de su utilidad para la formación de los residentes en el castillo de Calatrava, un aspecto que a nuestro juicio es de gran interés y no menos importante: Los universitarios de Calatrava.

Antes de entrar en este tema será necesario recordar otra circunstancia. Desde los últimos años del siglo $\mathrm{xv}$, la Corona ostenta ya la titularidad de la administración general de la orden con todo to que ello comporta; lo señalamos como un punto interesante del que ahora no vamos a tratar, aunque creemos que es necesario no olvidarlo por si la corte hubiera tenido aiguna influencia en la aparición de los universitarios de Calatrava.

En el capítulo general de la Orden celebrado en Burgos el año 1523 y en el de Valladolid del año siguiente, se tomó el acuerdo de enviar a tres freyles a estudiar Artes, Teologia y Cánones a la Universidad de Alcalá de Henares, por un periodo de siete años. Estos jóvenes estudiantes serían elegidos por el prior del convento y debían estar acompanados en la Universidad de un religioso de Calatrava de mayor edad. Era el denominado "anciano de estudiantes", a quien incumbia la obligación de controlar sus estudios y su formación general ${ }^{10}$.

Al mismo tiempo que se adoptó esta medida, se reforzaba la enseñanza para los que se quedaban en el castillo de Calatrava. Eran conscientes de la necesidad de mejorar la formación del propio clero. Hasta el punto que por vía indirecta se pretendía estimular su preparación intelectual; así el prior estaba obligado a premiar el esfuerzo y seleccionar a los conventuales más y mejor instruidos para desempeñar los cargos de mayor responsabilidad los prioratos formados, esto es, los que tenían rentas propias, o las rectorías, las iglesias parroquiales, de mayor importancia.

10 Francisco Fernandez IzQuiedo, obra citada, pág. 283 y ss., donde estudia en extenso esta cuestión. 
Esta primera experiencia universitaria se amplia a partir de 1552, con la creación de un colegio de Calatrava en la Universidad de Salamanca. A los tres estudiantes de Alcalá hay que añadir los ocho envíados a Salamanca por un periodo de ocho años. En este caso les acompañaría un rector del colegio en unión con otras personas a su servicio. El convento de Calatrava correría con lo asignado al rector, a los colegiales y al servicio. Esta organización de maestros en el convento y de estudiantes en las universidades citadas, exigia la adquisición de libros, tanto impresos como manuscritos, para cubrir las necesidades de la enseñanza.

\section{EL DOCUMENTO}

El manuscrito que contiene el inventario de los libros del Sacro Convento de Calatrava forma parte del legajo 4.401 del Consejo de Ordenes Militares del Archivo Histórico Nacional de Madrid. Se encuentra mezclado con un buen número de documentos elaborados todos ellos por el escribano o escribanos de los visitadores, en visita cursada durante el año 1526.

A pesar de su perfecto estado de conservación, le faltan los primeros folios. En estos folios desaparecidos podrían figurar el nombramiento de los visitadores, el mandato para realizar la visita, las razones para inventariar la biblioteca y las instrucciones correspondientes para los visitadores. La importancia de los extremos señalados e ignorados por nosotros nos llevan a prescindir de noticias que nos parecen de interés porque, los actuales visitadores dejan constancia de que con anterioridad a ellos, otros habían realizado un inventario de la biblioteca; constatan además la imperfección del mismo por la ausencia de ciento sesenta y un libros, y afirman que estos "no son de los que declararon (ellos) que faltaron al tiempo de su visitación" ".

11 "Averiguándose este inventario con el que hicieron frey Gonzalo del Arroyo, comendador de Daymiel e frey Alonso Valençuela, visitadores pasados, hallamos que hay çiento e sesenta e un libros de que no se hace mençión en el dicho su inventario, ni son de los que declararon que faltaron al tiempo de su visitación". Conviene retener el nombre de frey Gonzalo del Arroyo, comendador de Daimiel, porque le veremos disfrutar de un préstamo de veintinueve libros de la biblioteca del convento, libros que le fueron reclamados por vía expeditiva por los visitadores que confeccionaron nuestro inventario. 
El inventario se ha realizado siguiendo el orden de los "vancos" en que estaban colocados los libros, aunque debido a la mutilación del manuscrito, comienza con el último asiento del "quinto vanco". En cada "vanco" había unos veinte volúmenes por lo que hemos calculado que debian estar anotados otros cien volúmenes más de los que nosotros damos en el inventario que transcribimos. En las hojas que faltan debia de figurar también la fecha en que se procedió a realizar el inventario. En el primer folio que conocemos, con letra de finales del siglo XVIII, alguien escribió: "año yncierto". Nosotros podemos afirmar con toda certeza que este tardío amanuense no leyó el documento. Al final del folio $104 \mathrm{v}$, dice el escribano de los visitadores: «Pusieronse más en la dicha librería oy jueves, catorçe dias del mes de junio de mill e quinientos e veynte e seys años, otros nueve libros...". Todavía en el fol. $111 \mathrm{v}$ se indica de nuevo: «...ponerlo en la dicha librería en jueves, catorçe de junio de mill e quinientos e veynte e seys anos". Por tanto, el inventario se realizó el día 14 de junio de 1526 .

El documento es original y está escrito sobre papel. Se trata de un cuaderno confeccionado a base de bifolios que con anterioridad al uso que se les dio, debian de estar destinados a otra finalidad. El manuscrito tiene dos paginaciones: una con letra y otra con números arábigos. Los bifolios están paginados con un tipo de letra distinta a la utilizada por el escribano que realiza el inventario. Así, el primero de los bifolios conservados es el "quarenta y syete" e incluye los folios $47 \mathrm{r}-47 \mathrm{v}$ y $48 \mathrm{r}-48 \mathrm{v}$; el segundo es el "qurenta y ocho" e incluye el folio $49 \mathrm{r}-49 \mathrm{v}$ y $50 \mathrm{r}-50 \mathrm{v}$, con números arábigos hechos por el amanuense que escribe el inventario.

El manuscrito está perforado en el lugar y forma acostumbrado para pasar la cuerda que debía unir este cuaderno al resto de los documentos resultantes de la visita cursada al Sacro Convento de Calatrava y a otros lugares del señorio.

La escritura es humanista, clara y a una sola columna; con amplios margenes a izquierda y derecha, utilizados éstos por el escribano para hacer algunas anotaciones de gran interés para un mejor conocimiento de la biblioteca y su funcionamiento. En un estudio comparativo de éste con otros inventarios de bibliotecas, podemos afirmar que los visitadores tenían gran interés en hacer un inventario minucioso, indicando el título, el autor, aunque fuera con el nombre vulgar o mal escrito, y algunas características externas, con el fin de poder identificar todos y cada uno de los libros que pasaban por sus manos; respondiendo, a nuestro entender, a las exigencias impuestas por las personas que les habian enco- 
mendado este trabajo. Se trataba de controlar la biblioteca y de evitar las acciones de los lectores desaprensivos que convertian en suyo to que era propiedad del convento. A pesar de este buen hacer de los visitadores, este inventario como la mayoría de los documentos dedicados a este tema, anotan títulos perfectamente conocidos para ellos y de difícil identificación para nosotros, porque lo resumen a su manera, lo traducen mal, lo dan tal y como se conocía entre los escolares o citan autores con nombre abreviado, sin adscribirles ninguna obra concreta o anotan títulos sin autor alguno. Parece que se ha usado del viejo esquema inventarial a base de una persona que dicta el título con las caracteristicas de cada libro y de otra que lo anota. Unas veces la ignorancia y otras la prisa y poco cuidado del "dictador», del que dicta, o del «anotador», ponen en aprieto a los futuros lectores interesados en conocer las piezas inventariadas.

\section{LOCALIZACION Y NORMATIVA DE USO}

A tenor de las anotaciones marginales que encontramos en el manuscrito, la biblioteca estaba situada en la planta alta del convento; lo que hoy denominamos sala de lecturas se encontraba en la planta baja. Se podian sacar los libros del convento mediante un sistema de préstamo.

\subsection{Localización}

En el momento de hacer este inventario había dieciocho libros "abajo para la liçión" y una Biblia "en el refectorio". Entre los libros que estaba "abajo", junto a los que podíamos calificar de literatura religiosa, que son los más abundantes, encontramos a los clásicos latinos, una Ética de Aristóteles, a Boecio en su obra de Consolación o el De casibus 
virorum illustrium de Boccacio ${ }^{12}$. La variedad de títulos de este grupo nos hace pensar en la existencia de una verdadera sala de estudio o lectura. Que algunos libros estén "quemados" lleva consigo la existencia de algún sistema de "calefacción" en esta misma sala e implica descuido o despiste de los lectores en el tratamiento de los volúmenes. La localización de una Biblia en el refectorio concuerda muy bien con la normativa que obliga a guardar silencio en este recinto ${ }^{13}$.

No tenemos noticias acerca de si se puede o no identificar esta sala con aquella en la que los colegiales conventuales recibian las lecciones de sus maestros. Dada la existencia de aquéllos y de éstos podemos aventurar la identificación de las salas.

El capítulo general de la orden de 1511 recoge la preocupación de los conventuales por salvaguardar la integridad de su biblioteca, integridad que se resentía con excesiva frecuencia ya que la desaparición de los libros les obliga a tomar unas medidas ciertamente drásticas relativas al orden en la "librería", a la custodia de los libros y al sistema de préstamo.

Ignoramos cuál fuera la disposición anterior de los libros en la biblioteca; debemos de suponer, no obstante, que existiria un sistema de colocación de los volúmenes, aunque no debía de ser muy adecuado. Los capitulares en el capítulo de 1511, "mandaron que en la libreria del convento se hagan unos vancos en que se pongan los libros" ${ }^{14}$. Sabemos que durante los años que median entre la celebración del citado capitulo y el año 1526, data del inventario que nosotros conocemos, se ha puesto

12 Estaban abajo: Sermones quadragesimales. Disputadas de Sancto Thomas. Marial de Alberto Magno. Tulio de Ofitiis. Boccaccio de casibus virorum illustrium. Salustio sin comentario. El Siculo. Ethica de Aristoteles. De Virginitate Beatae Virginis. Leonardus Flo. rentinus de Flagellis Dominici. Libro de la vida de los Padres. Oracional de Hernand Pérez. Compilación del governamiento de los principes. Doctrina para servir a Dios. Tesoro. Boecio de consolación (dos ejemplares). Lógica en romance.

${ }^{13} \mathrm{La}$ obligación de guardar silencio en el refectorio está recogida en varias definiciones. En el capitulo general de 1511 (AHN, Códice 813-B) en el de Burgos de 1523 (Biblioteca de Santa Cruz de Valladolid Ms 335). En ninguna ocasión hemos visto referencia alguna a que durante el tiempo dedicado a las distintas comidas diarias se procediera a la lectura pública para entretener el silencio obligatorio, pero la presencia de una Biblia en esle lugar puede asociarse con esa práctica común en la vida conventual.

${ }^{14}$ AHN. OO. MM. Códice 813-B, fol. 53 (foliación a lápiz). A propósito de los muebles de las bibliotecas medievales puede verse: Jean-François GENEST, "Le mobilier des bibliotheques d'après les inventaires medievaux", en "Etudes sur le vocabulaire intellectuel du Moyen Age", II, Vocabulaire du livre et de l'écriture au Moyen Age. Actes de la table ronde, París, 24-26 de septiembre de 1987, Editorial Turnhout, Belgique 1989, págs. 136-154, especialmente págs. 146 y 152. 
en práctica aquel mandato capitular, así el escribano pudo anotar que "estan estos diez e nueve volúmenes susodichos en el quinto vanco siguiente de la dicha libreria” " Constatamos el cumplimiento de lo ordenado por el capítulo pero no podemos determinar la celeridad o lentitud con que se procedió al establecimiento de los citados "vancos", porque carecemos de noticias entre ambas fechas. En cualquier caso sólo se menciona la existencia de ocho bancos, lo que a una media de veinte volúmenes por banco suponen unos ciento sesenta volúmenes; una pequeña cantidad, porque el resto, hasta un total de más de quinientos volúmenes, "se hallaron... en la dicha librería fuera de los dichos van$\cos »{ }^{16}$.

Parece que la sangría de libros era abundante y los responsables de la custodia de la biblioteca no encontraron otra vía mejor que la de solicitar y conseguir del citado capitulo que en la librería "se hicieran unos vancos donde se pongan los libros con unas cadenas porque no se pierdan como hasta agora se ha fecho". Todos los libros inventariados y localizados en "vancos" están atados con cadenas, los demás aparecen "sueltos e sin cadenas".

Los volúmenes están distribuidos dentro de la biblioteca siguiendo un orden establecido de antemano. A un lado están todos los libros impresos, los llamados "de molde" por los visitadores. Le siguen los manuscritos. A continuación los prestados al comendador Arroyo y al bachiller frey Pedro Piñar y los que dejó a su muerte el maestro frey Marcos Ruiz ${ }^{17}$.

${ }^{15}$ AHN. OO. MM. Consejo, legajo 4401.

16 lbidem.

17 Parece que el desorden en to tocante a los libros de Calatrava se extendia a otros extremos que queremos recoger en nota por si sirvieran de aclaración. En el capitulo de 1511 (AHN, Códice 813-B, fol. 10) se dice: “De los libros de los religiosos del convento si seran del Sacristán o del convento. En la definición que habla de los derechos del sacristan del convento fue dicho por parte de los religiosos de él que el dicho sacristán por virtud de la dicha definición que mandaba que aya todos los libros del maestre y caballeros y freyres de la dicha orden que por ella tomaba los libros de los freyles conventuales que morian que no se solía hacer porque la definición lo impedia; y por parte del dicho sacristán fue dicho que la definición hablaba generalmente sin hacer distinción de freyles conventuales $e$ otros algunos. Fue acordado por el dicho capítulo lo vean los del consejo y lo que acordaren se guarde". Lamentamos no haber podido llegar a conocer la resolución del consejo, pero con anterioridad a junio de 1526, data del inventario, la biblioteca aumentó el número de sus volúmenes con todos los libros que poseía el maestro frey Marcos Ruiz a la hora de su muerte; por tanto la resolución del consejo debió de ser favorable a la demanda de los conventuales y contraria a las aspiraciones del Sacristán del convento. 
Lamentamos la mutilación inicial del manuscrito porque ello nos impide conocer la prelación en la colocación de los libros dentro de los bancos y con cadenas; esta predilección nos ayudaría, sin duda, a determinar qué tipo de libros eran objeto de distracción frecuente ya que los responsables decidieron iniciar por este grupo de volúmenes la acción de "atarlos con cadenas" ${ }^{18}$. Con toda prevención y tomando como punto de partida la actual distribución de los libros según el inventario, nos atrevamos a aventurar que entre los elegidos eran mayoría los títulos de derecho; no descartamos que entre los libros a proteger hubiera algunas ediciones valiosas de la citada o de otras disciplinas, que a juicio de los responsables de su custodia, debieran gozar de mayor protección.

\subsection{La normativa de uso}

El mandato recibido por los visitadores para inventariar la biblioteca debía de contener algunas cláusulas en las que no faltaría la dureza, ni en el fondo ni en la forma, no sólo para que su trabajo lo realizaran con minuciosidad, sino también para que actuaran expeditivamente contra los usurpadores de los libros. Al final de este inventario aparece una lista de ciento sesenta libros que no figuraban en el inventario anterior con el que éstos comparan su actividad inventarial. Podia valer la opinión de que estos volúmenes se corresponden con las adquisiciones de los dos últimos años; a nuestro entender sería un número de compras muy elevado para un espacio de tiempo tan corto. Parece más acertado pensar que los libros no anotados por los visitadores anteriores estaban fuera de la biblioteca. La recuperación de estos títulos pudo llevarse a buen término debido a la existencia de algún sistema de control sobre los libros que se habían sacado del convento.

No tenemos la normativa por la que se regulaba el acceso de los calatravos a los libros de la biblioteca; contamos, en cambio, con noticias

18 Jean-François GENEST, obra citada, pág. 147. 
ciertas de su funcionamiento práctico, al menos en lo relativo al sistema de préstamo ${ }^{19}$.

Los veinte libros que tenía frey Gonzalo del Arroyo, comendador de Daimiel, habian sido sacados de la biblioteca del convento según la normativa vigente, ya que para poder llevar los volúmenes a su casa-encomienda "dexó conosçimiento firmado de su nombre" ${ }^{20}$. En este documento de préstamo se consignaba no solo el título sino también el contenido de cada uno de los libros que se le prestaban. Este sistema sirvió para que el escribano de los visitadores pudiera anotar: "Otro libro... que dice en su conosçimiento que era de cartas". Pero el préstamo incluia otras obligaciones. Los visitadores, preocupados por completar el total de volúmenes prestados al citado comendador, proceden de la manera siguiente: "otro libro que se llama Salustio que se truxo en lugar de un quaderno de pergamino que hablaba de montería". El beneficiario del préstamo estaba obligado a entregar otro libro en lugar del que había perdido. Al mismo tiempo podemos pensar que Daimiel en esta época tenía un comendador no sólo aficionado a la lectura sino que además disponía de una biblioteca personal que se vería disminuida por la acción de los intransigentes visitadores de la Orden. ¿Debemos entender esta forma de actuación de los visitadores como una medida ejemplificadora? Lo cierto es que los calatravos con responsabilidades institucionales, estaban obligados a llevar una contabilidad de las rentas de la encomienda a su cargo por exigencias estatutarias ${ }^{2 t}$. Se procede a hacer el inventario

19 Agustín Millares CaRlo, Introducción a la historia del libro y de las bibliotecas. México 1971, pág. 259. Citando a 1. EsCAGüEs, "Un reglamento del siglo xıv para el préstamo de libros", Revista de bibliografia nacional, V, Madrid 1944, págs. 489-498, reproduce el texto de Juan Martínez, arcediano de Lorca en la iglesia de Cartagena, que cedió sus libros a la citada iglesia en octubre de 1392, estableciendo, si fuera necesario, un sistema de "préstamo de garantias".

20 AHN. OO. MM. Consejo, legajo 4401.

21 Además de lo señalado en la nota anterior, son muy abundantes los párrafos de las definiciones que hacen referencia a la obligación de llevar cuenta de los bienes de la Orden. Para no extendernos en exceso en la reproducción textual, indicamos solamente los lugares donde pueden encontrarse. AHN. OO. MM. Calatrava, Registro de Escrituras, V, 1345-C, fols. 26r-27v, 31 de diciembre de 1304. Joseph F. O'CALLAGHAN, "The earlies "Definiciones" of the order of Calatrava, 1304-1383", en The Spanish Military Oro'er of Calatrava and its affiliates, VII, pág. 265. AHN. OO. MM. Calatrava, Registro e Escrituras, VI, 1346-C, fols, 25r-26r. Definiciones del abad Juan de Palazuelos del 18 de octubre de 1325. Joseph F. O'CALLAGHAN, obra citada, pág. 269. Queremos recoger por último la registrada en AHN. OO. MM. Calatrava, Registro de Escrituras, VIII, 1348.C. Definiciones dadas en Almagro el dia 8 de septiembre de 1386. Joseph F. O'CALLAGHAN, obra citada, págs. 281 y ss., porque en ella se establece la obligación de hacer un inventario de los bienes de la encomienda a la hora de la toma de posesión "con carta partida por $\mathrm{ABC}$, una que la tenga 
de los libros para salvaguardar un bien de la Orden, y éste parece ser el sistema ideado no sólo para mantener la integridad de la biblioteca del Sacro Convento frente a los transgresores de la normativa de uso de los libros, sino también para los infractores del correcto uso de las escrituras de la Orden ${ }^{22}$.

A tenor de lo que precede nada debe extrañarnos que los libros que tenía el comendador Arroyo fueran incorporados a la biblioteca por frey Juan de Valdepeñas, mayordomo de la encomienda de Daimiel, quien había sido enviado por el convento para recuperar los volúmenes en número igual al de los prestados. Del mismo modo que procedió frey Bernardino Serrano que "truxo seys libros de los que tenía el bachiller frey Pedro Piñar». Entendemos que, en una y en otra ocasión, los que recuperaron los libros no hacian más que cumplir la misión que se les había encomendado.

\section{LOS LIBROS}

La mutilación inicial del documento nos impide conocer el número exacto de volúmenes de la biblioteca del Sacro Convento de Calatrava.

el maestre y otra el comendador, para dar cuenta cuando le fuere demandada". Se establece un verdadero juicio de residencia.

22 Nos parece ilustrativo recoger aqui la normativa emanada del capitulo del año 1511 (AHN. Códice 813-B, págs. 22 y ss.), sobre “las escripturas" por la similitud existente en el desorden de las mismas y en el deseo de evitarlo: "En la definición que habla de las escripturas del convento perdidas... y cómo su alteza es obligado a rebocarlas porque en la conservación dellas consiste todo el estado de la horden... fue fecha amonestación a todas las personas de la horden que presente estavan declaren todas las escripturas que tienen o saben que tienen en poder de otros... que los dichos llaveros cada y quando que por el dicho mandamiento dieren a sacar alguna escriptura resçivan conosçimiento de a quien la da, señalando término en que la traiga so la pena que para ello le fuere puesta... y si al tiempo que quedó obigado no truxese la tal escriptura, que a su costa envien una persona para la cobranza de ella y de la pena en que incurrió... y pasado el dicho término aviendo traido la dicha escriptura los dichos llaveros dentro de treinta días después de pasado el dicho término, envien a su alteza o al Consẹio el conosçimiento e obligación de la tai persona so pena de dos mill maravedis para que se provea cómo se cobre... Otrosi que los dichos llaveros traigan a cada capitulo relación de las escripturas que se han sacado fuera... Otrosi que el dicho capitulo mande a los dichos llaveros vean el sumario de las dichas escripturas y las repasen las que estan en el archivo para que se vea si falta alguna... Otrosi por quanto después acá se an ganado otras muchas escripturas, les fue mandado... ayan información de las que asi se an ganado y las anoten y pongan en el dicho sumario por la orden que estan las otras... Otrosi fue acordado que por quanto en los capitulos pasados se havia ordenado que para mejor guarda que será bien que de todas ellas se hiciere un libro escripto en pergamino...". 
El cálculo, apuntado más arriba, nos indica que serian unos cien libros los consignados en los folios que faltan, lo que nos sitúa en torno a los quinientos cuarenta volúmenes. Hablamos de volúmenes y no de títulos porque en algunos libros impresos y en repetidas ocasiones en los manuscritos se incluyen dos o más obras del mismo o de autores diferentes.

Los manuscritos superan en número a los impresos, aunque no podemos dar cifras porque este extremo no está debidamente clarificado en el inventario. Unas veces el escribano de los visitadores, al final de cada asiento, dice: "de mano"; otras veces se sirve del rótulo general: "de mano" a modo de epígrafe y entre ellos aparecen algunos libros impresos. Creemos que esta situación se debe a un simple despiste del amanuense quien, habiendo colocado el título general «de mano» o «de molde", se olvidó de cerrarlo o de corregirlo con posterioridad.

En una época en la que no habia una perfecta delimitación de las ramas del saber, resulta aventurado concretar el número de títulos correspondientes a cada disciplina. Una sola obra podía incluir en su sumario varios temas de filosofía, alguno de teología o de derecho. Por añadidura y apoyándonos en la estructura del inventario que conocemos, podemos aventurar que en los folios que le faltan al marnuscrito predominarian los títulos de derecho, seguidos de los de teologia, filosofia y libros de sermones. Ya hemos indicado que en los bancos de la biblioteca se colocaron en primer lugar los libros impresos. Entre éstos, y siguiendo ol inventario conservado, aparecen sólo veinte volúmenes de derecho hasta el registro núm. 60 y después no vuelven a aparecer, salvo casos aislados, hasta los asientos correspondientes a los manuscritos.

La distribución de volúmenes por disciplinas que damos a continuación podría ser sometida a todo tipo de variaciones, por tanto ha de tomarse como simple orientación global:

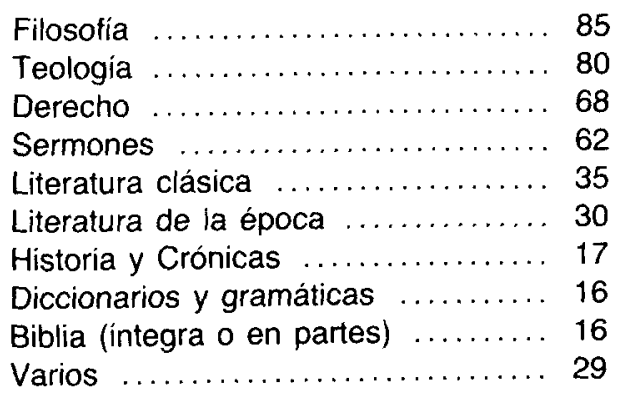


Sería de gran utilidad disponer de los ejemplares que en el inventario se registran a fin de proceder a hacer algunos comentarios, no sólo de las obras cuanto de las posibles anotaciones que pudieran aparecer en alguna de sus páginas, realizadas por los calatravos que hicieran uso de los mismos. Desconocemos, sin embargo, cuál haya podido ser el destino último de los libros de la biblioteca de Calatrava y mientras no dispongamos de noticias ciertas sobre este extremo cualquier hipótesis nos parece aventurada.

El proceso de identificación de las obras y de los autores no ha sido tarea fácil y por ello nos ha quedado incompleta. A parte de la razón apuntada en el párrafo que precede, muchas veces el inventario cita determinado autor sin asignarle ninguna obra concreta, en cuyo caso tampoco hemos querido aventurar una asignación. Otras veces se cita una obra sin autor; es el caso del asiento núm. 13 donde se dice: “Digesto viejo, con glosa»; lo mismo podíamos decir de los asientos 26 y 27 relativos al "Digesto nuevo, con glosa» o al "Codigo, con glosa". Tanto los Digestos como el Codigo son obras de Justiniano, pero ignoramos quién escribió las glosas que les acompañan. Otro tanto nos ocurre con algunas otras obras como la de Graciano del asiento núm. 61: “Un Decreto, con su glosa".

El lugar de la impresión y el año de edición no aparecen por ello en las anotaciones que hacemos al pie de página, damos una fecha de impresión siempre anterior al año 1526, que corresponde a la data del inventario de la biblioteca, fecha que debe entenderse a mero título orientativo y a tenor de lo que hemos visto en otras publicaciones especializadas ${ }^{23}$ que nos han servido de guía para la identificación de las obras y los autores.

\section{LOS AUTORES}

Presentamos un índice albafético incompleto de autores porque no nos ha sido posible llegar a una más completa identificación: unas veces

${ }^{23}$ Biblioteca Nacional de Madrid.

José Janini y José Serrano, con la colaboración de Ascario M. Mundo, Manuscritos litúrgicos de la Biblioteca Nacional, Madrid 1969.

abelardo Palanca Pons y María del Pilar Gomez Gomez, Catálogo de los incunables de la biblioteca universitaria de Valencia, Universidad de Valencia, 1981.

María de las Nieves Alonso Cortés, Catálogo de los manuscritos de la biblioteca de 
se nos proporciona sólo el nombre, otras el mote escolar, otras un apellido polivalente lo que unido a un título de la obra a medias, nos sitúa ante la asignación hipotética.

Los especialistas en esta materia, con certeza, hubieran superado airosamente este aspecto hostil del inventario, al menos en lo tocante a los libros impresos. Los menos expertos no hemos podido superar estas dificultades en su totalidad. En cuanto a los libros manuscritos, especialmente aquellos que contienen varios títulos, la posibilidad de una identificación aceptable, por el momento, está fuera de nuestro alcance. Ello no implica, ciertamente, que renunciemos a intentarlo en otra ocasión puesto que sería proseguir un camino ya iniciado por otros autores ${ }^{24}$.

Agni, Johannes de, 87, 94

Alfonso X, El Sabio, 73, 313, 318, 319, 328, 341, 356

Aliaco, Petrus de, 398, 410

Anania, 28

Anchona, Agustin de, 200, 208

Arcediano, 3

Aretio, Angelus de, 5

Arimino, Gregorio de, 371, 387

Aristóteles, 21, 41, 45, 56, 127, 131, 174, 240, 283, 337, 429

Aven Ruyz, 131

Bergamo, Jacobo Felipe de, 20

Bernardino de Siena, 47

Bernardo Adeugenium, 97

Biarte, Franciscus Nicolai de, 245

Blasco, Juan de, 265

Santa Cruz, Valladolid 1976.

Saturnino Rivera Manescau, Incunables y Raros, Valladolid 1970.

Francisco VINDEL, Cien obras de la colección Massó, Madrid 1940; ID, XX incunables de la colección Massó, Madrid 1948.

Antonio PALAU y DuLCET, Manual del librero hispanoamericano, Barcelona 1954.

Nicolao Antonio, Biblioteca Hispana Nova, Madrid 1793.

Antoninus, Biblioteca Hispana Vetus, Torino 1963.

Jean-Charles BRUNET, Manuel du libraire e de l'amateur de livres, Paris 1860-1864.

Dictionaire droit canonique, tomo I-V, Paris 1935-1950.

Dictionaire theologie catholique, París 1923-1945.

Agustín Millares Carlo, Introducción a la historia del libro y de las bibliotecas, México 1971. Hay reimpresión de 1981.

Pedro Bohigas, El libro español. (Ensayos históricos), Barcelona 1962. 1989.

${ }_{24}$ Julián Martín ABaD, Manuscritos en España. Guía de Catálogos impresos, Madrid 
Boccaccio, Giovanni, $81,120,346$

Boecio, 196, 203, 246, 345, 351, 366, 409

Bruno de Arezzo, Leonardo, 56

Bruxellensis, Joannes, 421

Caracciolus, Roberto y Liccio, Franciscus Roberto de, 115, 125, 292

Cartagena, Pablo de, 306

Catón, Publio, 281

Cesolis, Jacobo de, 293

Cicerón, Marco Tulio, 119, 126, 298, 427

Colonna, Guido de, 221, 272, 338

Cornazano, Antonio de, 110

Diaz de Montalvo, Alfonso, 166, 297

Dato, Agustín, 112

Durando, Guillermo, 75, 388

Esopo, 281

Estrabón, 36

Fabro, Jacobo, 408, 414, 430

Fernández de Palencia, Alonso, 25, 42

Florencia, Antonio de, 204

Galiensis, Joannes, 203

Gallus, Alexander, 247

Gandía, Pedro de, 208

García de Santamaría, 315

Gerson, Joannes de, 372, 404

Gorran, Nicolás de, 382

Grit, Franciscus Joannes de, 100

Halberstat, Conrado de, 157

Hartmann Schedel, 43, 59

Heralt, Joannes, 83

Inghenn, Marsilius de, 171

Inocencio IV, 14, 233

Josefo, Flavio, 38

Justino, 69

Juan Herminio, 223

Limos, Andrés de, 428

Lira, Nicolás de, 186, 404

Lombardo, Pedro, 53, 86, 147, 259, 284

López de Ayala, Pedro, 363

Llul, Ramón, 18, 54, 94, 95, 209, 211, 228, 258, 269, 276, 278, 327, 432

Madrigal, Alonso de (El Tostado), 359

Magistris, Joannes de, 419

Magistris, Martino de, 46, 397, 411 
Manetti, Bianzo, 348

Mantua, Bautista de, 145, 399

Marchia, Francisco de, 214

Marcial, 426

Mayrones, Francisco de, 85, 291

Mediavilla, Ricardo de, 403

Mediolano, Francisco Miguel de, 35, 101

Monte Brixiensis, Pedro de, 16, 29, 36

Nebrixa, Antonio de, 23, 24, 33, 113, 122, 137, 143, 144, 316

Ockan, Guillermo de, 253, 370, 373, 374, 375, 376, 391, 404

Orosio, Paulo, 224

Ovidio, Publio, 192, 234

Parisiensis, Guillermus, 364, 384, 385, 386, 404

Perguliensis, Pablo de, 142

Petrarca, Francisco de, 294, 435

Pisa, Rainiero de, 39

Pisa, Uguccione de, 103

Plinio, 60, 146

Polonus, Martinus, 32

Porta, Sancho, 254

Prisciano, 230

Ptolomeo, 73

Purbachi, Jorge, 76

Pérez de Guzmán, Hernand, 299

Quintiliano, Marco Flavio, 63, 42.4

Quinto Curcio, Rufo, 302

Reacli, Joannes, 130

Romano, Egidio, 222, 300, 307, 309, 344

"Sacristán", D. Bartolomé, 305

Sacrobusto, Juan de, 76

Sajonia, Alberto de, 410

Sajonia, Ludolfo de (El Cartujano), 34, 82, 360

Salustio, 132, 314

San Agustín, 169, 205, 250, 285, 286, 287, 369

San Aberto Magno, 118, 142, 155, 198, 212, 288, 389

San Anselmo, 65

San Benito, 282, 336

San Bernardo, 279, 395

San Buenaventura, 98, 109, 134, 140, 148, 335, 379, 380, 381, 410

San Gregorio, 67, 78, 149, 225, 262, 268, 343, 394

San Isidoro de Sevilla, 256, 277

San Jerónimo, 368 
San Vicente Ferrer, 9, 51

Santaella, Rodrigo de, 31

Santillana, Marqués de, 279

Santo Tomás, 44, 53, 68, 74, 88, 99, 102, 105, 163, 170, 181, 241, 290

Scoto, Duns, $72,90,135,150,392,393,400$

Sedulio Tarentus, Basilio, 410

Séneca, Lucio, 322, 329, 342, 347, 405

Sículo, Diodoro, 128, 160

Sículo, abad, 6

Sículo, Lucio Marineo, 160, 167

Taterenti, Petrus de, 378

Terencio, 12, 123

Textoris, Guillermo, 121

Tito Livio, 70, 71, 354

Torquemada, Juan de, 390

Valencia, Jacobo de, 124

Valerio Maximo, 58, 296

Vauveris, Felipe de, 114

Vegeccio Renato Flavio, 312

Virgilio, 139, 164

Vorágine, Jacobo de, 84, 106

Vorilong, Guillermus de, 62, 76

Ximénez de Prexano, Pedro, 19

Utino, Leonardo de, 66, 129, 261 


\section{INVENTARIO *}

(1) Secunda parte sermonum ortulus regine, dominical y santoral.

Estan estos diez e nueve volumenes susodichos en el quinto vanco siguiente de la dicha libreria e todos con sus cadenas.

\section{Sesto vanco}

(2) Otras decretales con su glosa.

(3) Arcediano sobre el decreto.

(4) Otro Sexto de las decretales con su glosa.

(5) Angelus de Aretio: de Malefitis, con otro tratado del mismo de testamentis y otro tratado llamado facisculus (sic) medicinae. Todos tres tratados en un volumen.

${ }^{*}$ ) En la publicación del inventario de la biblioteca hemos respetado el orden y el sistema de los asientos. El número entre paréntesis que precede a cada asiento es nuestro y to hemos colocado para facilitar la lectura; tos números de las notas al pie de página se corresponden con aquellos. En estas notas al pie de página destacainos aquellas obras o autores que en el documento original aparecen de dificil identificación y no hacemos mención a aquellos autores y obras cuya identidad nos la facilita el propio inventario.

(2) Podria tratarse de Giovanni D'ANDREA, Clementis papae V constitutiones (clementinas), con una glosa ordinaria. También podría ser Enrique DE SUSA, llamado el Hostiense, Suma super titulis decretaitum.

(4) Podría tratarse de Giovanni D'ANDREA, profesor en Bolonia, con su obra: Glosa in Sextum 
(6) Exposición del abad Sículo sobre el tercero de las decretales.

(7) Un decreto con su glosa.

(8) Otros decretales con su glosa.

(9) Sermones Vicentii de tempore pars hiemalis e pars estiualis. Dos cuerpos en un volumen.

(10) Sexto y Clementinas con su glosa e Instituta con su glosa. Tres cuerpos en un volumen.

(11) Fasciculus temporum.

(12) Terencio con exposición de Donato y Calfurnio.

(13) Digesto viejo con su glosa.

(14) Aparatus Inocentii super quinque libros decretalium.

(15) Zabarcla sobre las clementinas.

(16) Secunda pars repertorii utriusque iuris, Petri Vixençis.

(17) Tratatus clausurarum juris vitalis de Cabanis. Exposicio Filini de Fide instrumentorum. Ambos cuerpos en un volumen.

(7) Se trata del Decreto de Graciano. Ignoramos el autor de la glosa.

(8) Ver no. 2.

(9) San Vicente Ferrer. Lugduni 1493.

(11) Este tipo de obras, juntamente con los titulados "calendarios" son publicaciones muy frecuentes en el siglo xv. Una de las obras más difundidas con este mismo título es la de ROLEWIK DE LAER, Werner. Se editó en Sevilla por Bartolomé de Segura y Alfaro del Puerto el año 1480 . Ver no. 77.

(12) PALAU recoge esta publicación con los mismos comentaristas que apunta el inventario y señala dos ediciones: Milán 1476 y Barcelona 1498.

(13) Ignoramos a quién puede pertenecer la glosa sobre la obra de Justiniano.

(14) Sinibaldo DE FIESCHI, maestro en Bolonia y más tarde papa con el nombre de Inocencio IV (1243-1254). Glosó la complicación gregoriana con el título: In V decretalium libros... comentaria.

(16) Podria tratarse del autor Petrus de MONTE Brixiensis. 
(18) Otro Arbor scientiae de Reymundo.

(19) Confutatorum errorum contra claves eclesiae.

(20) Suplementum coronicarum.

(21) Problemas de Aristóteles con exposición de Pedro de Ebano.

(22) Nova practica iuris.

Estan estos veinte e un volumenes de libros susodichos en el sexto vanco siguiente de la dicha libreria asydos con sus cadenas.

\section{Setimo vanco}

(23) Dos partes del vocabulario de Antonio de Nebrixa de latín y de romance, en un volumen.

(24) Arte de Gramática con comentario del dicho Nebrixa.

(25) Vocabulario de Alonso de Palencia.

(26) Digesto nuevo con glosa.

(27) Codigo con glosa.

(18) Ramón LluL compuso esta obra en Roma entre septiembre de 1295 y abril de 1296. Se editó en Barcelona en 1482 y 1505.

(19) Podría tratarse de Pedro Jimenez de Prexano, obispo de Coria, Confutatorum errorun contra claves ecclesiae nuper editorun, Toledo 1486.

(20) Jacobus Philipus de Bergamo, Suplementum cronicarum, Venecia 1490. La versión castellana de este libro se hizo bajo el título: Suma de todas las crónicas del mundo, Valencia, por Jorge Costilla, traducida de lengua latina y toscana en esta castellana por Narciso Viñoles, 1510 (Vindel).

(24) Antonio DE NEBRIJA, Gramática con comentario, Barcelona 1497.

(25) Alonso FERNÁNDEZ DE PALENCIA, Vocabulario universal en latín y en romance, Sevilla 1490 .

(26 y 27) Ignoramos a quiénes pueden pertenecer las glosas sobre las obras de JusTINIANO. 
(28) Anania sobre el quinto de las decretales.

(29) Prima pars repertorii Petri Vixencis de propietatibus rerum.

(30) Sermones Thesauri novi dominicales.

(31) Vocabularium magistri Roderici de Santaella de vocabulis bibliae.

(32) Tabula martiniana super decretum.

(33) Otro vocabulario de Nebrixa. Dos partes en latín y en romance.

(34) Otra vita Christi cartuxano.

(35) Sermones Michaelis Mediolanen.

(36) Strabón de situ orbis.

(37) Margarita poetarum.

(38) Josepho de bello judaico.

(39) Otra suma parva Rayneri de Pisis.

(40) Vocabularium utriusque iuris.

(41) Textum ethicorum Aristóteles.

Estos veinte e dos volumenes de libros suso escriptos estan en el septimo vanco de la dicha libreria asydos con sus cadenas.

(32) Martinus Polonus, Margarita decreti, seu Tabula Martiniana, Venecia 1486.

(34) Ludolfo DE SAJONIA, El cartujano. Esta obra fue traducida al castellano por Fray Ambrosio de Montesinos, Alcalá de Henares 1502.

(35) Michael de CaRcano o Michael Mediolanensis, Sermonariun de decem praeceptis per quadragesiman, Venecia 1492. Ver nota 101.

(38) La obra de Flavio Josepho fue traducida al castellano por el cronista Alonso de Palencia en 1492.

(40) Palau dice que aunque se atribuye a Antonio de Nebrija, parece una obra anónima. Se publicó en Venecia en 1512 .

(41) Se editaron en Zaragoza 1473-1475. Ver no. 16. 


\section{Octavo vanco}

(42) Otro vocabulario de Alonso de Palencia.

(43) Suma coronicarum.

(44) Expositio Sancti Thome super libros ethicorum et expositio Egidii Romani super libros retoricorum Aristóteles, en un volumen.

(45) Textus philosophiae naturalis Aristóteles con interpretación del Jacobo.

(46) Martinus de Magistris de fortitudine.

(47) Sermones beate Bernardini de Senis.

(48) Versori quaestiones en philosophia natural.

(49) Otros sermones de thesauri novi de Sanctis.

(50) Vocabularium catholicorum.

(51) Otros sermones Vicentii.

(52) Pandeta medicorum.

(53) Otro texto magistri sentenciarum cun exposicione litterali Sancti Thome.

(42) Ver no. 25.

(43) Podria tratarse de la obra de Hartmann SCHEDEL, Liber chronicarum, Norimbergae 1493. A juicio de Vindel la obra más monumental del siglo $\mathrm{xV}$, desde el punto de vista tipográfico.

(44) Podría referirse a la edición cuyo título sería: Egregi doctor Sancti Thome de Aquino in libris ethicorum, Barcelona 1478.

(45) Fabro STAPULENSE (Jacobo), In hoc opera continetur totius philosophiae naturalis paraphrases... VIII phisicorum Aristóteles, Alcalá de Henares 1510.

(51) San Vicente FERRER, Sermones de tempore et de Sanctis, Venecia 1496.

(53) Se trataria de un comentario de Santo Tomás a la obra de Pedro Lombardo, Quatour libri sentanciarum. 
(54) Ars inventiva magistri Raymundi en pergamino y de mano.

(55) Stellarium corone Beatae Mariae virginis.

(56) Textus ethicorum Aristóteles et traduccione Leonardi Aretino. En pergamino y de mano.

(57) Otros sermones thesauri novi de Sanctis.

(58) Otro Valerio Maximo con Tulio de ofitiis, senectute et amicitia en un volumen.

Están estos diez e siete volumenes de libros susodichos en el octavo y último vanco de la dicha libreria con sus cadenas asidos.

Los libros que se hallaron sueltos e syn cadenas en la dicha libreria fuera de los dichos vancos son los que siguen:

(59) Otra suma coronicarum historiada y de marca grande.

(60) Plinio de la natural historia, de marca grande.

(61) Decreto con su glosa.

(62) Guillermo Virilon super libros sentenciarum.

(63) Declamaciones Quintiliani.

(64) Viola anime.

(54) Se tiata de la obra de Ramón Llul Ars Inventiva veritatis, escrita en Mompellier en 1298. Al ser un libro copiado a mano no podemos indicar a qué edición podría referirse.

(56) Creemos que se trata de Leonardo Bruno de Arezzo, comentarista de Aristóteles, Textus ethicorum e traductione de Leonardo Aretino, Barcelona 1480, o Ethica ad Nicomacum con traducción de Leonardi Aretini, París 1496.

(59) Igual que en el no. 43, ahora nos parece que debe tratarse de la obra de Hartmann SCHEDEL, Liber Chronicarum. Norimbergae 1493. De ella dice el escribano de este inventario que está "historiada" y Vindel que tiene más de dos mil grabados.

(60) Cayo PLINIO, Glosa iiteralis in primun et secundun naturalis historiare libros, Alcalá de Henares 1524.

(61) Ignoramos a quién puede pertenecer la glosa sobre la obra de Graciano.

(62) Guillermo VoRILLON, Super quatuor libros sentenciarum, Venecia 1496.

(63) Marco Flavio QuintIliano, Institutiones Oratoriae, Venecia 1493. Palau recoge muchas ediciones de esta obra con el título de "Declamaciones". 
(65) Opuscula Beati Anselmi.

(66) Sermones aurei de Sanctis.

(67) Moralia de San Gregorio.

(68) Secunda pars Sancti Thome.

(69) Justino histórico.

(70) La primera década de Tito Livio en toscano.

(71) La tercera década de Tito Livio en toscano.

(72) Scotus pauperum super libros sentenciarum.

(73) Quatri partitum Ptolomei. Tablas del rey don Alfonso. Dos cuerpos en un volumen.

(74) Tabula aurea operum Sancti Thome.

(75) La terçera parte del especulador. (Al margen derecho: Está en el segundo vanco que se puso alli).

(76) Repertorius magistri Guillermo Vorilog. Sphera parva Joannis de Sacrobusto. Theorice planetarum Georgi Purbachi. Todo en un volumen.

(77) Facisculus temporum.

(78) Dialogus Sancti Gregorii. Autoritates liber Aristóteles. Todo en un volumen.

(79) Novius Marcelius. Arte de Antonio de Nebrixa. Entramos cuerpos en un volumen.

(66) Leonardo DE UTINo, Sermones aurei de Sanctis, Vicentiae 1480.

(68) Santo TOMÁs, Suma theologica. Secunda pars, Venecia 1480.

(75) Se trata de la obra de Guillermo DuRando.

(77) Ver nota 11

(78) San Gregorio, Dialogi de Viris Sanctis et de eorum miráculis, Paris 1495. 
(80) Suma de exemplis et similitudinibus.

(81) Joan Vocatio dei Florio et Bliancafiori, en toscano.

(82) Otra via christi cartujano.

(83) Sermones discipuli de tempore et de sanctis.

(84) Lombardica historia y leyenda sanctorum. Agustini de Trinitate. Dos cuerpos en un volumen.

(85) Quadragesimale iluminati doctores Francisçi de Mayrones. De marca de medio pliego.

(86) Textus magistri Sentenciarum. De marca de pliego.

(87) Janua artis y formalitates breves y metaphisica et tratatus de magistri Joannes de Agni. Todo en un volumen de marca de quarto.

(88) Terçia pars suma Sancti Thome cun aditione Dominici de Fladia. De marca de pliego en un volumen.

(89) Especulum exemplorum.

(90) Scoto sobre el segundo y el tercero de las sentencias. De marca de medio pliego en un volumen.

(91) Sermonarium de comendacionem virtutum et reprobacione vitiorum. De marca de quarto.

(92) Mamotretus. De marca de quarto.

(81) Giovanni BocCACCIO, Filocolo. Compuesto durante su estancia en Nápoles (c. 1336). Es una adaptación en prosa del tema medieval de Floris y Blancaflor.

(82) Ver no. 34.

(83) Joannes Heralt, Sermones discipuli de tempore et de Sanctis. Promptuaria exemplorum et de miraculis Beatae Virginis Mariae, Lugduni 1485 y 1497, Nuremberg 1492.

(84) Jacobo dE VORAGINE, Leyenda aurea Sanctorum. También se la conoce con el título de Lombardica historia porque incluye una crónica de Lombardía. Igualmente se le llama Leyenda aurea.

(86) Pedro LOMBARDo, llamado «magister sententiarum». 
(93) Sermones thesauri novi quadragesimales.

(94) Otra janua artis metaphisca magistri Joannes de Agni. Tractatus de Concepcione Beatae Virginis magistri Raymundi. Todo en un volumen de marca de quarto.

(95) Disputacio heremite ex Raymundi in libros sentenciarum. Proverbia Raymundi. Todo en un volumen de marca de pliego.

(96) Sermones vademecum de marca de medio pliego.

(97) Ars bene moriendi expositio canonis misae Bernardus Adeugenium prefectus religiosorum. De marca de ochavo.

(98) Sermones Sancte Boneventurae. Sin cobertor.

(99) Sanctus Thomas super ethica Blondinus. Todo en un volumen cubierto de pergamino.

(100) Sermones quadragesimales Françiscus Johannes Grit. De marca de quarto. (Al margen izquierdo: abaxo para la liçion y no se ha de poner en el inventario).

(101) Sermones quadragesimales Françiscus Michaelis de Mediolano. De marca de quarto.

(102) Suma angelica. De marca de quarto.

(103) Suma pisano que se llama suplementum canones penitencialos. Todo en un volumen de marca de quarto.

(104) Luminare majus. De marca de pliego.

(94) Ramón LluL, De Laudibus Beatissimae Virginis Mariae, París 1499.

(95) Ramón LluL, Quaestiones dubitabiles insuper quatuor libris sentenciarun..., Lugduni 1491. Id. Proverbia, Barcelona 1493.

(100) Franciscus Johannes GritsCH, Quadragesimales, Venecia 1495.

(101) Michael de Carcano o Michel Mediolanensis, Sermoniarum de decem praeceptis per quadragesiman, Venecia 1492.

(103) Podría tratarse de la Suma de Uguccione de PISA. Glosador canonista italiano de gran renombre. 
(105) Disputadas de Santo Tomas de virtutibus. Marca de pliego. (Al margen izquierdo: esta en el primer vanco).

(106) Marial de Jacobo Voragine. De marca de medio pliego.

(107) Itinerarium terrae sanctae. De marca de pliego.

(108) Prima pars sermonum de laudibus sanctorum, janua artis formalitates breves. Todo en un volumen de marca de quarto.

(109) Opuscula Sancti Bonaventurae.

(110) Cornazano de re militari, en toscano. De marca de ochavo.

(111) Una biblia. De marca de quarto. (Al margen izquierdo: En el refectorio).

(112) Liber Beati Bernardi de verbis Simonis Petri ad Johannum. Elegancias de Agustino Dato. Un tratado de re militari. Todo en un volumen de marca de quarto. pliego.

(113) La parte del vocabulario de Nebrixa en romance. De marca de

(114) Philipus de Vauveris con una colección de indulgencias de la orden. Todo en un volumen de mano y de molde.

(115) Sermones Françisco Roberti. De marca de quarto.

(116) Otro façisculus temporum. De marca de medio pliego.

(117) P. Floreto con exposición. De marca de medio pliego.

(118) Marial de Alberto Magno. De marca de quarto. (Al margen izquierdo: abaxo para la liçion).

(106) Jacobo de VORAGINE, Leyenda aurea sanctorum seu Mariale, Venecia 1480.

(110) Antonio Cornazano, Opera bellissima del arte militar, Roma 1493.

(115) Ver nota 125.

(118) San Alberto Magno, Marial seu de laudibus Beatae Mariae Virginis, Argentine (Estrasburgo) 1493. 
(119) Tulio de Ofitiis con comentario. De marca de pliego. (Al margen izquierdo: para la liçion).

(120) Juan Vocatino de cassibus virorum ilustrium. De marca de pliego. (Al margen izquierdo: abaxo para la liçion).

(121) Sermones de pasione Domini Guillermi Textoris. De marca de quarto.

(122) Vocabulario de Nebrixa, emtramas partes el qual habia llevado el comendador Arroyo de este convento con otros libros por los quales fue frey Juan de Valdepeñas y los truxo según iran adelante en este inventario declarados.

(123) Terencio, sin comentario. Epistolas de Plinio con unas epistolas de mano. Todo en un volumen.

(124) Jacobo de Valencia sobre el psalmista.

(125) Homilias comunes sermones quadragesimales de frey Roberto, en toscano. De marca de quarto.

(126) Otro Tulio de Ofitiis con comentario. De marca de pliego.

(127) Autoridades de Aristóteles sacadas de todas sus obras. De marca de quarto.

(128) Diodoro Sículo. De marca de pliego.

(129) Sermones quadragesimales de legibus Leonardo Lentino. De marca de pliego.

(120) Giovanni Boccaccio, De casibus virorum illustriun. Esta obra fue traducida por el canciller Pedro López de Ayala con el título Desventuras de los hombres ilustres.

(125) Roberto DE LICIO o Robertus CARACCIOLUS, Sermones quadragesimales de poenitencia, Venecia 1485. 1476.

(128) No indica título, pero su obra más difundida fue Bibliotheca historica, Venecia

(129) Podría tratarse de Leonardo de Utino. 
(130) Sphera mundi theorica planetarum de verbo mirifico Johannis Reacli. Todo en un volumen de marca de pliego.

(131) Ethica de Aristóteles con exposición de Auen Ruiz e política. Todo en un volumen de marca de pliego.

(132) Salustio sin comentario. De marca de quarto. (Al margen izquierdo: abaxo para la liçion).

(133) Efemerides de astrologia. De marca de quarto.

(134) Sermones de comuni sanctorum de san Buenaventura. De marca de quarto.

(135) Quotlibetos de Scoto. De marca de quarto.

(136) Sermones quadragesimales de floribus. De marca de quarto.

(137) Otro vocabulario de Nebrixa, entramas partes de latín y de romance. De marca de pliego.

(138) Suma de exemplis. De marca de ochavo.

(139) Virgilio con comentario. De marca de pliego.

(140) Dieta salutis sancti Bonaventura. Sermones sancti Agustini ad heremitas. En un volumen de marca de ochavo de pliego.

(141) Otro mamotreto de marca de quarto.

(142) Lógica Pauli Perguliensis. Suma philosophia Alberto Magno. Todo en un volumen de quarto.

(143) Arte vieja Nebrixa. De marca de pliego.

(144) Otra arte de Nebrixa de la misma forma con comentario.

(135) Duns Scoto, Quaestiones Quotlibetales, Venecia 1498. 
(145) Baptista Mantuano pertinice historia betica Caroli Verardici elegia Marcelini Verardi pasos de Mayrones. En un volumen de quarto de pliego sin tablas, ni cobertor y quemado por una parte.

(146) Plinio de la natural Historia.

(147) Textus Magistri Sentenciarum.

(148) Otra dieta salutis de ochavo.

(149) Expositio Gregorii papae super Ezequiel. De marca de quarto.

(150) Quarto de las sentencias de Scoto. De marca de quarto.

(151) Otra sphera mundi.

(152) Almanach perpetuo con otro tratado de astrologia en romance. De marca de quarto.

(153) Biblia pauperum y un diccionario pequeño de mano. Todo en un volumen de marca de quarto.

(154) De oculo morali. De ochavo.

(155) Compendium theologiae veritatis.

(156) Figurae bibliae. De ochavo de pliego.

(157) Concordancias de la biblia, desbaratadas y de marca de pliego.

(158) Dos partes del diccionario general de la Sagrada Escritura hasta la «c» $\sin$ cobertor y de marca de pliego.

(159) Sexto y Clementinas, con glosa. De marca de quarto.

(147) Pedro Lombardo. Ver nota 86.

(148) San Buenaventura. Ver no. 140.

(153) Biblia pauerum, Venecia 1510.

(155) San Alberto Magno, Compendium theologiae veritatis, Venecia 1485.

(157) Conradus de Halberstat, Concordantiae Bibliorum, Basilea 1496. 
(160) El Sículo, de marca de quarto.

(161) Otras homilias. De marca de quarto.

(162) Opusculum dominici hermani ordinis cartuxiensis. De marca de quarto.

(163) Quotlibetos de Santo Tomas. De marca de quarto.

(164) Virgilio con comentario. De marca de pliego.

(165) Otro mamotreto sin cobertor e roto. De marca de quarto.

(166) Repertorio de Montalvo. De marca de pliego.

(167) Crónica Siculi, de molde. Repertorium decreti, de mano. Repertorium Josephi de antiquitatibus, de mano. Todo en un volumen de marca de quarto.

(168) Doctrinal de marca grande y de pergamino y de mano.

(169) Meditaciones vita Jhesu. Liber sancti Agustini ad sanctum Paulinum episcopum de cura pro mortuis agenda. Todo en un volumen de mano.

(170) Quotlibetos de Sancto Tomas, de mano.

(171) Marsilio de generatione et corruptione, de mano.

(172) Una exposition sobre el psalterio sin titulo de pergamino y de mano.

(160) Ver no. 128 y también no. 167.

(166) Se trataria de un repertorio de la obra de Alfonso DiAz DE Montalvo, Compilación de las leyes del reyno. Emiliano GONZALEZ DiEZ en la presentación de la publicación facsimil de la obra de Montalvo, Valladolid 1986, recoge 14 ediciones de la obra del insigne jurista hasta 1523.

(167) Lucio Marineo Sículo, Crónica d'Aragón, Valencis 1524.

(168) Podría tener relación con el Doctrinal de Gramática del no. 247. También existe en este mismo inventario otro título: Doctrinal de Cavalleros. Ver no. 315.

(171) Marsilius DE INGHEN, Quaestiones in Aristotelis de generatione et corruptione. Venecia 1500 . Sería una copia manual de esta edición. 
(173) Una exposición sobre los evangelios, sin título. Paresçen homilias. De mano.

(174) Una ethica de Aristoteles de marca grande. (Al margen izquierdo: abaxo para la liçión).

(175) Sermones pugna virtutum et vitiorum magistri Marci. De quarto de pliego y de mano.

(176) Exposicio sobre el psalterio sin titulo, en marca de pliego y de mano.

(177) Mansiones filiorum israel, de mano.

(178) Quaestiones parisienses super libros ethicorum, de mano.

(179) Tratado de artes, sin título, de pergamino y papel y de mano.

(180) Un vitis patrum. De marca de pliego.

(181) Exposición de Santo Tomás sobre el octavo de la ethica. De marca de pliego y de mano.

(182) De diferentiis testamenti veteris inter christianos et hebreos de Nicolao de Lira. Tractatus de dictis antiquorum per qua probatur nativitas et predicatio et resurrectio Christi de Joannes Parisiensium. Todo en un volumen de quarto de pliego y de mano.

(183) Tractatus de çensura ecclesiastica abatis de Senis. De pliego $y$ de mano.

(184) Arbor sçiençiarum Reymundi. De pliego entero y de mano.

(185) Otro mamotreto.

(176) Podria tratarse de una copia manual de la obra de Juan DE TOROUEMADA, Expositio super toto psalterio. Roma 1470. Lo mismo podiamos indicar de los nos. 189 y 194.

(180) Podría tratarse por error del escribano, de Jacobo DE VORAGINE, De vitis sancto. rum. Venecia 1478. 
(186) Nicolao de Lira contra hebreos. Tratatus de offitio misae de mano. Todo en un volumen de marca de quarto.

(187) Gesta Salvatoris et miraculis Beatae Virginis. En pergamino y de mano.

(188) Quaestinones totius philosophia per ordinen alphabeti. En pergamino y de mano.

(189) Expositio sobre el psalterio. Sin título de marca de pliego y de mano.

(190) Casus Bernardi y Aparicius Petri super decretales. En pergamino y de mano.

(191) Sermones quadragesimales. Sin título y de mano.

(192) Epistolas de Ovidio con el de Ponto, en pergamino y por una parte quemado.

(193) Tratado contra Mahoma. Sin título, de ochavo y de mano.

(194) Una exposición sobre el salterio. De pergamino; de marca de medio pliego y escripto de mano y sin título.

(195) Tratado de heresibus con tratadillo de la regla de San Françisco. De mano.

(196) Suma Boetii. De marca de quarto y de mano.

(197) Sexto de las decretales. De marca grande pergamino y de mano. Esta intitulado encima «Decreto". no. 182 .

(186) Nicolao DE LIRA, Contra perfidiam ludaeorum, Venetia 1481. Del mismo autor ver

(191) Sermones de cuaresma es un título que se repite con frecuencia en este inventario y entre los autores de aquel tiempo. Esta circunstancia y el estar escrito a mano hace muy difícil identificar esta y otras obras de las que no se da más que el título.

(194) Ver 176.

(196) Podria tratarse de BoEcio, Opera. Venecia 1499. Copiada a mano. 
(198) Compendium de theologia veritatis de marca de quarto y de mano.

(199) Flos sanctorum en latin. En marca de pliego y de mano.

(200) Tratado de Agustino de Anchona sobre la magestad con otros de las questiones de la philosophia moral y otro contra judeos. De marca de medio pliego y de mano.

(201) Suma coloquiorum Joannis Galiensis. De marca de pliego y de mano.

(202) Postilla sobre bibliarum, sine autore. De pergamino y de mano.

(203) Boetio de consolation. De mano.

(204) Tabula totius sumae Antonii de Florencia con otra suma de la ethica y politica de Aristoteles. De mano.

(205) Exposición sobre el maestro de las sentencias. Sin título, en pergamino y de mano.

(206) Expositio Sancte Agustinii super canticum gradum. De mano.

(207) Sumarios de la Biblia, pequeñitos. En pergamino y de mano.

(208) Tratatus de Laudibus Virginis Agustini de Anchona. Otro tratado de Pedro de Candia. De mano y todo en un volumen.

(209) Ars generalis Raymundi. De quarto de pliego y de mano.

(210) Canonicus super libros phisici. De mano.

(198) San Alberto Magno. Ver no. 155.

(201) Podría ser una copia manuscrita de la obra de Joannes Gallensis, Suma de regimine vitae humanae, seu margarita doctorum. Venecia 1496.

(203) Al dar el título en castellano pensamos que podría ser una copia manuscrita a partir de la traducción realizada por Pedro LOPEZ DE AYALA.

(209) Ramón LLUL. 
(211) Raymundus. De mano.

(212) Alberto de natura et origine anime. De mano.

(213) Sermones. Sin título y de mano.

(214) Françiscus de Marchia super terçium sententiarum. De pergamino y de mano.

(215) Apocalipsis con unas teóricas. En pergamino y de mano.

(216) De Virginitate Beatae Virginis. En pergamino y de mano.

(217) Manipulus florum decreti. De mano.

(218) Tratatus de virtutibus secundum ordinum alphabeti. De pliego y de mano.

(219) Tratatus de temperancia. De marca de quarto y de mano.

(220) Suma pisana. De marca de pliego y de mano.

(221) Historia Troyana. De pliego y de mano.

(222) De regimine principum. En pergamino y de mano.

(223) Colectario de Juan Herminio. De marca de quarto y de mano.

(224) Paulo Orosio. En pergamino y de mano.

(225) Diálogos de Sanct Gregorio. En pergamino y de mano.

(226) Una obra en verso in laudem Christi et virtutum. En pergamino, de mano y sin guarnición.

(211) Sin título.

(220) Ver no. 103.

(221) Guido DE Colonna, Historia troyana. Pamplona 1489. Ver no. 272. Sería una copia manuscrita.

(222) Egidio Romano, De regimine principum. Roma 1482. Copia manuscrita.

(224) No nos da el título. Sería muy arriesgado asignar una obra. 
(227) Confutatio judeorum con otro tratadillo de çirugia. De mano y todo en un volumen sin cobertura.

(228) Tabula generalis magistri Raymundi. De mano.

(229) Un tratadillo de virtutibus theologicis. De mano.

(230) Una parte de Prisciano. En pergamino.

(231) Historia evangélica de concepcione precursoris Christi. En pergamino y de mano.

(232) Tratatus de heminentiae religionis con un tratadico de San Bernardo ad milites templi. De mano.

(233) Inocentio Quarto sobre el quinto de las decretales. De mano. Suma introductoria super offitio advocationis. De mano y todo en un volumen.

(234) Moralidades sobre Ovidio, metamorphoseos y otra suma sin título. De papel y de pergamino escrito de mano.

(235) Exposicio evangeliorum. En pergamino y de mano.

(236) Unas Decretales con un Sexto. En pergamino y de mano.

(237) Contra hereticam pravitatem del doctor de Villadiego. De mano.

(238) Una epístola del cardenal de Sanct Statio con un tratado de institutione regiminis dignitatum. En un volumen y de mano.

(239) Leonardus Florentinus de flagelis Dominici. De mano. (Al margen izquierdo: esta para la liçión).

(228) Copia manuscrita de una obra de Ramón LluL.

(230) Prisciano, Gramática. Aventuramos la asignación de esta obra al autor que se cita en el inventario, porque fue muy conocida y utilizada en la época de este inventario.

(232) Podría tratarse de la obra de SAN BERnaRdo, De laude novae militiae en la que el santo autor opone la caballería seglar a la caballería celestial de los templarios. 
(240) Una parte de la ethica de Aristóteles. De mano.

(241) Secunda secundae Sancti Thome abreviata. De mano.

(242) Himnos y Caton. De pergamino y de mano.

(243) Statuta cisterciensis ordinis. De pergamino y de mano.

(244) Utilis modus vivendi. De mano.

(245) Distinciones Françiscus Nicholai de Biarte. En pergamino y de mano.

(246) Expositio de Boetio. De mano.

(247) Gramática del Doctrinal. De mano.

(248) Liber divi Bernardi abbatis de consideratione. En pergamino y de mano.

(249) Confisionario. En pergamino y de mano.

(250) Liber amonitionis Sancti agustini. De pergamino y de mano.

(251) Un misal de pergamino y de mano.

(252) Instructio sermocinandi. De mano.

(253) Lógica de Ockan. De mano.

(254) Sermones de Sancho Porta. De mano.

(247) Podría referirse a un manuscrito de la obra de Alesander Gallus o VILLA DEI, Doctrinal de Gramática.

(252) Esta obra pertenece al conjunto de la actividad desarrollada por los gramáticos especulativos o "modistas", "así llamados por el interés especial que, hacia la primera mitad del siglo XIV, pusieron en la búsqueda de una filosofía del lenguaje basado en la relación entre palabras e ideas". (1. Beceiro Pita, pág. 276). No es fácil determinar quien pudo ser el autor que sirvió de modelo para la copia de este manuscrito; queremos destacar la abundancia de este tipo de obras. 
(255) Centones. De mano.

(256) Liber sentenciarum Isidori. En pergamino y de mano.

(257) Opera Theodori. De mano.

(258) De asçensu et desçensu Raymundi.

(259) Epilogus magistri sentenciarum. De mano.

(260) Un librito en pergamino. De mano y sin título.

(261) Leonardo Aretino. De mano.

(262) Otros diálogos de San Gregorio. En pergamino y de mano.

(263) Ars poetica. De mano.

(264) Unos sermones sin título. En pergamino y de mano.

(265) Tratado de Juan de Blasco iuris canocicibus. De mano.

(266) Un colectario chico en pergamino y de mano.

(267) Preceptos de gramática. De mano.

(268) Una parte de la exposición de los morales de Job en pergamino. Es un cuaderno suelto.

(256) San Isidoro de SeVILLa, Sententiarum libri III.

(258) Ramón LLUL, Liber de ascensu et descensu intelectus.

(259) Se trataría de un epilogo a la obra de Pedro Lombardo.

(260) Entre los libros manuscritos reseñados en este inventario son bastante frecuentes los que aparecen sin título. Si además falta el nombre del autor, la identificación se convierte en aventura.

(261) Si sólo conocemos el autor es muy difícil asignarle una obra. A Leonardo Aretino - Leonardo Bruno de Arezzo le hemos encontrado en traducciones de obras de Aristóteles y de Séneca. Sus obras más difundidas en su traducción al castellano fueron el Tratado de la caballeria, traducido por Pedro de la Panda y el de Bello italico adversus gothos, un resumen libre de la Guerra Gotica de Procopio. (1. Beceiro Pita, pág. 278). Ver no. 56.

(262) Ver no. 79 y 225.

(268) Creemos que se trata de un manuscrito a partir de San Gregonio Magno, Moralia, seu expositio in Job. 
(269) Formalitates magistri Raymundi. De mano. mano.

(270) Tratatus de signis complexis et incomplesis. Sin título y de

(271) Sumulas de lógica. De mano.

(272) Coronica Troyana. En pergamino y de mano.

(273) Otras súmulas en pergamino y de mano.

(274) Sermones secundum et consuetudinem cisterciensium. En pergamino.

(275) Un tratadillo de derecho con una novela y un tratadillo de la sphera. De pergamino y de mano.

(276) Ars generalis magistri Raymundi que no se puede leer.

(277) Sinonima Sancti Isidori, de mano y con otros tratadillos.

(278) Ars magna magistri Raymundi. De mano.

(279) Exemplario de Sanct Bernardo, con un tratado de los proverbios del Marqués de Santillana. De mano.

(280) Meditationes de factis Domini Nostri Jhesu Christi. Tratatus de Trinitate et incarnacione. De mano.

(281) Caton con las fábulas de Ysopo. En pergamino.

(269) Ramón LLuL, Libellus formalitatum per reverendum magistrum Petrus Degui Rajmundi Lulli.. editum. Queremos añadir el final de la portada de esta obra tal como la recoge PALAU: "Fratrem Martinus Almodovar ordinis militiae de Calatrava traditae impresoribus et per eos impresae Hispalis 1491". Esta pudo ser la publicación que sirvió para hacer el manuscrito que aquí se cita.

(272) Guido DE Colonna. Ver no. 221.

(276) Ramión LluLL.

(277) SAN ISIDORO, Sinonimorum de lamentatione animae pecatricis librill. Este libro podía servir no sólo para la formación espiritual sino también literaria de los predicadores.

(278) Ramón LLUL.

(279) Iñigo de Mendoza, Maroues de Santlllana (1398-1458), Proverbios.

(281) Esopo. Fábulas. 
(282) Regula sancti Benedicti. En pergamino.

(283) Ethica Aristoteles. De mano.

(284) Textus magistri sentenciarum. En pergamino y de mano. Maltratado.

(285) Tratatus de exemplis et proverbiis philosophorum. De marca pequeña en pergamino.

Hallaronse mas veynte e un libros de latin y de mano maltratados e que non se pueden bien aprovechar de ellos. (Al margen izquierdo: iojo!).

Pusieronse mas en la dicha libreria oy jueves, catorce dias del mes de junio de mill e quinientos e veynte e seys años, otros nueve libros de los quales traxo seys frey Bernardino Serrano de los que tenia el bachiller frey Pedro Piñar que son estos:

(286) Augustinus de Civitate Dei, con comentario. De marca de pliego guarnesçido con unas tablas e el cobertor de cuero colorado.

(287) Augustinus de Quaestionibus. De marca de medio pliego con unas tablas cubiertas de cuero envejado blanco.

(288) El Alberto Magno sobre los evangelios. De marca de pliego y encuadernado con cubiertas de cuero colorado.

(289) La primera parte del diccionario. Sin tablas de marca de pliego.

(290) Santo Tomás sobre las epistolas de San Pablo. De marca de pliego con unas tablas cubiertas de cuero envejado azul.

(291) Sermones Françiscus Mayrones. De marca de medio pliego con unas tablas cubiertas de cuero colorado viejo.

(282) Existen muchas ediciones de esta obra.

(284) Pedro Lombardo. 
(292) Sermones Roberti de laudibus altissimi Dei. De marca menor en cuaderno e cubierto de cuero blanco que to truxo el dicho frey Bernardino de Almagro de casa de su padre de frey Cristobal Lorençio, pitançero.

(293) Otro libro que comienza: «el tratado siguiente hizo e ordenó frey Jacobo de Çesulis, de la orden de los frayles predicadores, del juego de ajedrez y otras obras que se contienen en él. De romance escripto de mano, enquadernado en un cuero vayo. El qual asi mismo truxo el dicho frey Bernardino de Almagro de su casa del dicho padre de Christoval Lorençio, pitançero.

(294) Otro libro que falta para el número de los nueve libros que ansy se pusieron en la dicha librería está asentado delante en el inventario de los libros que dexó al convento el maestro frey Marcos Ruyz al cabo de él porque era de los del mismo maestro, el qual se llama Françisco Petrarca.

Suma de los libros que se hallaron sueltos y en romance en la dicha libreria.

\section{De molde}

(295) Libro de las vidas de los padres que to truxo frey Juan de Valdepeñas, mayordomo del convento de Daymiel, al tiempo que fue por los diez e nueve libros que el comendador Arroyo avia llevado del mismo convento por los quales dexó conosçimiento firmado de su nombre e dio este en lugar de uno que dice en el memorial de su conosçimiento que no tenia puesto nombre.

(296) Valerio de las historias escolásticas e de España que tambien lo truxo el dicho de mayordomo Daymiel en lugar de uno de tres libros

(293) Jacobo De Cesolis, Juego de Ajedrez. Dice Palau que la primera edición castellana de esta obra se remonta a 1473 bajo el título: Solacium ludi schocorum.

(294) Es muy aventurado indicar a cuál de sus obras pudiera referirse. 
que faltaron de los que ansi avia llevado el dicho comendador Arroyo que se decia el uno de los que ansi faltaron: La ethica de Aristóteles.

(297) Una compilación de leyes de estos reinos de Castilla.

(298) Tulio de Ofitiis.

(299) El oracional de Hernand Pérez. (Al margen izquierdo: esta abajo para la liçion).

(300) Regimiento de principes.

(301) Trabajos de Hércules moralizados con visión delectable e otra tratado de vida beata.

\section{De mano}

(302) Libro de la clarissima y pura retorica con Quito Curcio Rufo historial el qual es de los que habia llevado el dicho comendador Arroyo del convento e lo truxo el dicho mayordomo.

(303) Otro libro que comienza: "Las palabras del Eclesiastés». Esta guarnesçido en cuero negro e unos clavos que es de los que avia llevado el dicho comendador Arroyo.

(304) Otro libro que trata de confisiones, guarnesçido en un cuero colorado de los que avia llevado el dicho comendador Arroyo.

(297) Alfonso Diaz de Montalvo, Compilación de las leyes del reino, Edición facsimil, Valladolid 1986.

(300) Egidio DE Colonna o Egidio Romano, traducido al castellano en el siglo xIV por fray Juan de Castrojeriz. (S. Roubaud, "Les manuscrits du Regimiento de principes et l'Amadis", en Mélanges de la casa de Velázquez, V, 1969, págs. 207-222). Durante los siglos $x v$ y $x V I$ aparece esta obra como un tratado de enseñanza del buen gobierno en las colecciones de casi todos los magnates e incluso en la de personalidades ligadas a la corte (Beceiro Pita, pág. 278). En nuestro caso aparece varias veces, confirmando la opinión expresada. 
(305) Otro libro con unas cartas e unas coplas del sacristan don Bartolomé, de los que avia llevado el dicho comendador frey Gonzalo de Arroyo.

(306) Una coronica romana e de España, guarnesçida en cuero negro que se truxo de los que avia llevado el dicho comendador Arroyo.

(307) Un regimiento de principes, en cuero colorado guarnesçido, que se truxo de los que avia llevado el dicho comendador Arroyo.

(308) Otro libro sin título guarnesçido en cuero vayo e comiença: en la selva destruyda. Se truxo de los que avia llevado el dicho comendador Arroyo e dizen en su conosçimiento que era de cartas.

(309) Otro libro encuadernado en cuero vayo que habla del governamiento de los principes e se llama compilación del governamiento de los principes que se truxo de los que avia llevado el dicho comendador Arroyo. (Al margen izquierdo: para la liçión).

(310) Otro libro de doctrina para servir a Dios, guarnesçido en cuero colorado que se truxo de los que habia llevado el dicho comendador Gonzalo de Arroyo. (Al margen izquierdo: para la liçión).

(311) Un libro que tiene el principio en latín e comiença: Quidam e todo lo otro esta en romance con unas cartas de Hernando del Pulgar e çiertas conveniençias entre el maestre don Luis de Guzmán e la Horden con el cabildo e universidad de la Hermandad vieja de Ciudad Real que se truxo de los que avia llevado el dicho comendador Arroyo.

(305) El Sacristán don Bartolomé debió de ser un hombre culto y a lo que parece una persona preocupada por mejorar la preparación intelectual de sus compañeros de Orden. En 1497 o quizá antes, hizo donación de un juro de 25.000 maravedíes con lo que se pagaría a un lector de Theología y Artes para que instruyese a los monjes del Convento de Cálatrava.

(306) Cabe suponer que se refiere a la obra del obispo Pablo de CARTAGena, Suma de las crónicas de España. Abarca este libro desde los tiempos primitivos de España hasta 1412, pasando revista además a los monarcas fabulosos, a los emperadores de Roma y anotando otros acontecimientos relevantes de la antigüedad.

(307) Ver no. 300.

(309) Ver no. 300 y 307. 
(312) Otro libro que se llama: Vegecio de re militari, que se truxo de los que avia llevado el dicho comendador Arroyo.

(313) Una parte de la General Historia, que se truxo de los que avia llevado el dicho comendador Arroyo e contiene veinte e ocho libros en un volumen.

(314) Otro libro que se llama Salustio, que se truxo en lugar de un cuaderno de pergamino que hablaba de montería e lo avia llevado el dicho comendador Arroyo e porque aquel no se hayó al tiempo que fueron por estos libros, truxo el dicho mayordomo el dicho libro Salustio. (Al margen izquierdo: esta en los de abajo).

(315) Otro libro que se llama doctrinal de caballeros e árbol de batallas, todo en un volumen, el qual se truxo de Daymiel en lugar de otro libro que avia llevado el dicho comendador Arroyo que se llamaba Proemio a las epístolas de Séneca, e porque aquel non paresçio dio el dicho comendador Arroyo por él, este doctrinal.

(316) Con estos libros y un vocabulista de Antonia de Librixa e un misal pequeño romano, que se asentaron el vocabulista con los libros del latín que estaban sueltos en la librería que se contiene en el inventario antes que este en el misal con los libros de la sacristía, se cumplieron los diez e nueve libros que avia llevado del convento el dicho comendador Arroyo, los queales todos truxo frey Juán de Valdepeñas, mayordomo del convento.

(317) Una parte de la Biblia en romance desde el principio hasta los Macabeos, de marca grande.

(318) Fuero del rey don Alfonso, dos partes en un volumen.

(319) La segunda Partida del rey don Alfonso.

(312) Flavio VEgECIO RENATO, Liber de re militari. Ms. de la biblioteca de Santa Cruz de Valladolid.

(313) AlFonso X, Grande e General Historia.

(315) Puede tratarse de Garcia de SANTA MARIA, Doctrinal de Caballeros e árbol de batallas. Burgos 1489 .

(318) ALFONSO $X$. Uno de las formas de reconocimiento del Libro de las Partidas porque su título original fue: Fuero o Libro de las leyes.

(319) Ver anterior. 
(320) Libro de Josué.

(321) Libro de la epistola que embio Castor, obispo de Opia. (Al margen izquierdo: para la liçión).

(322) Epístolas de Séneca a Lucillo, sin prinçipio.

(323) Libro de los pecados e irregularidades en que pueden caer los religiosos.

(324) Libro de Valerio de las señales que siguen aquéllos que entienden.

(325) Libro sin principio que en la primera hoja comiença: «esquivar las codicias que están encadenadas".

(326) El libro de los quatro hermitaños.

(327) Libro de la doctrina pueril. (Al margen izquierdo: Cartillas).

(328) Otro fuero del rey don Alfonso.

(329) Libro de las tragedias de Séneca.

(330) Proverbios de Séneca.

(331) Libro que comiença: "Introducción al diálogo y razonamiento entre el noble e generoso señor don Fernand Alvarez de Toledo, conde de Alva, etc".

(332) Libro llamado Lucidario que compuso el rey don Sancho.

(333) Libro sin comienzo que es parte de la Biblia.

(334) Libro de doctrina Christiana.

(322) PALAU registra las ediciones castellanas de Zaragoza 1496 y de Toledo 1502

(327) Ramón LLUL, Libro de la doctrina pueril.

(328) Ver no. 318. 
(335) Libro llamado Estímulo de Amor que compuso San Buenaventura.

(336) Regla de San Benito.

(337) Ethicas de Aristóteles.

(338) Historia Troyana.

(339) Libro de la inmortalidad del ánima e de las negligencias de los sacerdotes en la misa.

(340) La coronica sumaria de los reyes y emperadores del mundo.

(341) Fuero del rey don Alfonso.

(342) Libro de Luçio Séneca de la vida Bienaventurada.

(343) Los Morales de San Gregorio, en pergamino.

(344) Segundo libro de Regimiento de Principes.

(345) Libro de Boeçio.

(346) Libro que comienza: “todo hombre, según dice Aristóteles".

(347) La primera tragedia de Séneca.

(348) Diálogos de Bianzo Maneti. En toscano y en pergamino.

(349) Libro llamado: «Fiometa», compuesto por Juán Bocaçio. En pergamino y en toscano.

(350) Una parte de la Biblia sin cobertor y sin comienço. Ilano.

(336) PaLAU registra la edición de Monserrat de 1499 como la más antigua en caste-

(338) Guido de Colonna. Ver no. 272.

(340) Ver no. 306.

(341) Ver no. 318.

(349) Giovanni Boccaccio, Fianmeta. 
(351) Otro Boeçio de Consolación. la Biblia.

(352) Otro libro que se llama Coronica de los Reyes en el libro de

(353) Libro llamado de los viçios y virtudes.

(354) La primera parte de Tito Livio.

(355) Una parte de la Biblia que comienza: «Del noveno capítulo del libro de Josué».

(356) La segunda parte de la General Historia.

(357) Otro libro de visión delectable.

(358) Libro llamado Thesoro, que habla de la nobleza de todas las cosas. (Al margen izquierdo: para la liçión).

(359) Confisyonario del Tostado.

(360) Vita Christi cartuxano, sin principio.

(361) La sexta Partida del rey don Alfonso.

(362) Otro libro llamado Isayas Propheta.

(363) Coronica de España que habla del rey don Juan y del rey don Pedro.

(351) Al dar el título en castellano podría tratarse de la traducción hecha por el canciller Pedro López de Ayala.

(353) Podria tratarse de Hernand Pérez de Guzmán, Coplas de vicios y virtudes a la muerte del obispo de Burgos.

(356) Ver no. 313.

(359) Alonso de Madrilgal, El Tostado, Confesional. Salamanca 1498.

(360) Ludolfo de SAJONIA, El Cartujano. Alcala de Henares 1502.

(363) Puede referirse a la de Pedro Lopez de Ayala, Crónica del rey don Pedro. 
(364) Libro de los evangelios y epístolas de todo el año.

(365) Una parte de la Biblia desde el Génesis hasta el libro de Job.

(366) Otro Boeçio de Consolaçión. (Al margen izquierdo: para la liçión).

(367) Un libro de lógica en romançe. (Al margen izquierdo: para la liçión).

Inventario de los libros que se hallaron de los que fueron del maestro frey Marcos Ruiz en la dicha libreria, los quales todos son de papel e de molde.

(368) Dos cuerpos de las epistolas de San Gerónimo, en dos volúmenes.

(369) Opus quaestionum divi Augustini. Enquadernados en pergamino.

(370) Libro de Ockan yntitulado Opus noveginta dierum, con otro tratado suyo yntitulado Defensiones curatorum.

(371) Gregorio de Arimino super secundum sentenciarum.

(372) Tres partes del Gerson; la primera parte con el repertorio de sus obras en un volumen y las otras dos en un volumen cada una.

(373) Ockan sobre el primero de las sentencias con la tabla de sus obras y un tratado suyo yntitulado Centilogium theologicum.

(364) Guillermus PARISIENSIS, Evangelios y espistolas de todo el ario, traducidas por Gonzalo García de Santa María. Zaragoza 1485. Añade Palau una edición de 1908 con esta introducción: "Evangelios y espistolas con sus exposiciones en romance, según la versión castellana del siglo xv, hecha por Gonzalo Garcia de Santa Maria del texto de Guillermus Parisiensis: "Postilla super epistolis et evangelia", ahora de nuevo publicada conforme a la edición de Salamanca de 1493".

(368) SAN JeRónimo, Epistolas. Traducción del bachiller Juán de Molina. Valencia 1515.

(371) Ver no. 387

(372) Podria tratarse DE Jeán de Gerson, De potestate ecclesiastica escrita en 14161417 durante el Concilio de Costanza. Su pensamiento mantiene una estrecha vinculación con la escuela ockanista. 
(374) Otro libro de Ockan intitulado Dialogus magistri Guillermi de Ockan.

(375) Quotlibeta Guillermi Ockan.

(376) Tratatus logicae Guillermi de Ockan.

(377) Burleius super octo libros phisicorum.

(378) Quaestiones magistri Petri Taterenti super philosophiam et metaphisicam.

(379) El primero de las sentencias de San Buenaventura con la tabla de los quatro libros de las sentencias en un volumen. volumen.

(380) El segundo de las sentencias de San Buenaventura en otro

(381) El terçero de las sentencias del mismo en otro volumen. Todos estos quatro volúmenes enquadernados en pergamino.

(382) Postillas de Nicolai de Gorran super epistolas Pauli.

(383) Libro yntitulado liber novae retoricae.

(384) Guillermus Parisiensis de Universo.

(385) Guillermus Parisiensis de Sacramentibus con otro tratado del mismo yntitulado Cur Deus homo, e otro del mismo yntitulado De moralitate anime. Todos en un volumen.

(386) Liber Guillermi Parisiensis de Fide, de Legibus, de Virtutibus, etc. Todo en un volumen. Todos estos tres cubiertos de pergamino.

(374) Guillermus DE OCKAN, Disputatio inter clericun et militiae super potestate prelatis atque principibus terram conmisa sub torma dialogi. Colonia 1478. Dice Brunet que algunos autores lo han impreso con el título de Diálogos en vez de disputaciones.

(377) Gualter BuRleIus. Ver no. 412. 
(387) Primero de las sentencias de Gregorio de Arimino.

(388) Durandus super quatuor libros sentenciarum, por enquadernar.

(389) Compéndium theologiae veritatis. Cubierto de pergamino.

(390) Quaestiones super evangeliis totius anni de Turrecremata. Cubierto de pergamino.

(391) Ockan super secundum et tertium et quartum sentenciarum, con un tratado de unitate intelectus Sancti Thome de Aquino.

(392) Scotus super secundum sententiarum, cubierto de pergamino.

(393) Scotus super tertiun sententiarum, cubierto de pergamino.

(394) Moralia Gregorii super Job.

(395) Obras de San Bernardo, por enquadernar.

(396) Opus epistolarum beati Bernardi, cubierto de pergamino.

(397) Martinus de Magistris De Temperantia ytem de Fortitudine. Todo en un volumen.

(398) Otro Petrus de Aliaco super quatuor libros sententiarum.

(399) Baptista Mantuano de Beata Virgine Maria.

(400) Quotlibeti Scoti, cubierto de pergamino.

(401) Latatius Firmianus.

(402) Un libro sin título que contiene libros de lógica de diversos autores.

(387) Ver no. 371.

(388) Guillermo DuRANDO, uno de los grandes glosadores civilistas.

(389) San Alberto Magno. Ver nos. 155 y 198.

(390) El cardenal Juan de TORQUEMADA.

(394) San Gregorio Magno. 
(403) Ricardus de Mediavilla super quartum sentenciarum.

(404) Nicholaus de Lira super decalogum de pasionis anime de Gerson. Interrogationes doctrinae Ockan de Sacramentibus. Resolutorium dubiorum dialogus Guillermi Parisiensis. Todo en un volumen de ochavo cubierto de pergamino.

(405) Seneca de quatuor virtutibus, con otros tratados. Uno de quatuor novisimis ytem super reformationes status monastici ytem de artibus magistris, etc., con un catholicon de latin en francés. Todos en un volumen.

(406) Epistolae Françisci Nigri Stephanus Fliscus Robertus Gagninus. Todo en un volumen cubierto de pergamino.

(407) Arithmetica Jordani.

(408) Musica Fabri.

(409) Arithmetica Boetii ex Fabro geometria Bravardini. Todo en un voiumen cubierto de pergamino.

(410) Mercurius Trimagistri, phisica parva Albert, magistri Petrus de Aliaco de anima. Sermones Sancti Boneventurae de morte. Basilio Sedulio Tarentus de intençione et remisione. Con otros dos tratados uno de Albert de Saxonia y otro de arithmetica. Todo en un volumen cubierto de pergamino.

(411) Tratatus predicabilium Martini de Magistris, con otro tratado de consequencias del mismo. Todo en un volumen cubierto de pergamino.

(412) Expositio Burleius super libros ethicorum.

(413) Quaestiones Buridani super libros ethicorum.

(414) Paraphrases Fabri super libros ethicorum.

(412) Gualterius Burleius. Ver nota 377

(414) Jacobo Fabro Stapulensis, Philosophia naturalis paraphrases, París 1504. Ver no. 430 y 437 . 
(415) Quaestiones super libros politicorum incerto autore.

(416) Tratatus spherae sin comentario. Theorica planetarun sin comentario. Todo en un volumen cubierto de pergamino. Fol. $111 \mathrm{r}$.

(417) Copulata de lógica.

(418) Comentum emendatum et correttum in primun, etc.

(419) Sumulae magistri Johannes de Magistris.

(420) Cornucopia.

(421) Expositio magistri Johannes Busellensis super logicam de Aristóteles.

(422) Comentum magistri Johannes super sumulas.

(423) Aulio Gelio.

(424) Quintiliano con comentario.

(425) Lucanus cum comento.

(426) Martialis cun comento, sin coberturas.

(427) Tulio de Ofitiis, de Senectute, de Amititia cun comento.

(428) Andrei Limos Valentinensis insolubilia.

Allende de estos dichos libros de molde se hallaron escriptos de mano en la dicha libreria que heran del dicho maestro frey Marcos Ruiz los que se siguen: tóteles.

(429) Un libro sin título que es quaestiones sobre la lógica de Aris- 
(430) Un libro que al principio tiene un tratadico de molde yntitulado: "Ars moralis Jacobi Fabri", con otros tratados de letra de mano. Todo en un volumen cubierto de pergamino.

(431) Un libro que contiene muchos tratados de mano que comiença: "prima ordinaria». Cubierto de pergamino.

(432) Compendiosa geometria magistri Raymundi.

(433) Un libro sin titulo que comiença: "Ductıs est Jhesus in desertum". Es de romance, con otro tratado que comiença: "Conclusiones de este tratado". Asi mismo es de romançe cubierto de pergamino.

(434) Un libro que al principio tiene unas letras ginesas que dicen Marcos Ruiz. Cubierto de pergamino.

(435) Otro libro que se llama Françisco Petrarca, de marca de pliego, con unas tablas guarnesçidas de cuero colorado, que hera de dicho maestro frey Marcos Ruiz e gelo avia prestado a Gonzalo Fernández de Córdova e él lo hizo traher de Argamasilla a este convento e ponerlo en la dicha libreria en jueves catorce de junio de mill e quinientos e veinte e seis años. Es este libro de latín.

E despues de hecho este inventario del dicho maestro frey Marcos Ruiz, truxo frey Lucas Ferrandez dos libros que son estos:

(436) Un enquadernado en tablas cubiertas de cuero envexado colorado viejo que contiene quatro volúmenes que es el primero: "quaestiones logicales super libros posteriorum Aristotelis". E otros tres tratados que estan en marca de quarto.

(437) Otro libro de marca de quarto enquadernado en pergamino que es: "Paraphrases de Fabro sobre la philosophia natural de Aristóteles".

(438) Hallose otro libro que era del dicho maestro que son las Tragedias de Séneca.

(430) Jacobo Fabro StaPulensis. Ver nota 414.

(437) Ver nota 414. 